\title{
NUEVOS DATOS PARA LA DEFINICIÓN DE LA ETAPA FINAL DEL BRONCE EN CARMONA (SEVILLA)
}

\section{NEW EVIDENCE FOR THE DEFINITION OF THE LATE BRONZE AGE IN CARMONA (SEVILLA)}

por

\author{
ALEJANDRO JIMÉNEZ HERNÁNDEZ
}

\begin{abstract}
RESUMEN A partir del análisis de una nueva secuencia estratigráfica se examina el contexto estratigráfico y cultural de "Cogotas I" en Carmona (Sevilla) y su relación con el Bronce Final tartésico.
\end{abstract}

ABSTRACT We examine the stratigraphic and cultural context of "Cogotas I" in Carmona (Seville) and its relation with the tartesic Late Bronze Age through the analysis of a new stratigraphic secuence.

\section{INTRODUCCIÓN}

La importancia de Carmona como yacimiento clave para el conocimiento histórico en el Bajo Guadalquivir, ha sido reiteradamente manifestada en multitud de trabajos que ineludiblemente toman como referencia el yacimiento. A este respecto, los trabajos, ya clásicos, de Carriazo y Raddatz en el Raso de Santa Ana (1960) y los cortes CA-80/A y B (Pellicer y Amores, 1985), han servido, y sirven, de apoyo para sostener teorías diversas y muchas veces contrapuestas, para apuntalar cronologías y, en definitiva, han sido el paradigma del yacimiento. Cierto es que han sufrido múltiples revisiones que, por lo general, se han centrado en los artefactos recuperados, pero éstas no han abordado la causa real del agotamiento científico al que hemos sometido dichas secuencias, que es su indefinición estratigráfica.

La existencia de un equipo estable en Carmona desde 1985, ha permitido una exhaustiva y constante exploración arqueológica de la ciudad cuyos resultados se han ido publicando en los Anuarios Arqueológicos de Andalucía pero, a pesar de que la información ahí vertida proporciona datos muy clarificadores, no se han tenido, por lo general, en consideración para dinamizar la imagen científica del yacimiento. La firma de un convenio entre el Ayuntamiento de Carmona y el Departamento de Prehistoria y Arqueología de la Universidad de Sevilla y, posteriormente, la aprobación de un Proyecto General de Investigación para la ciudad, han incidido en una revitalización de los estudios arqueológicos, ante todo en su difusión científica.

Este trabajo es un primer apunte de un proyecto más general del estudio de la Prehistoria reciente en 
Carmona. Los objetivos que nos planteamos se centran en aportar una nueva información extraída de una de las secuencias estratigráficas obtenidas en el yacimiento, que permiten precisar la secuencia cultural de los últimos momentos del Bronce, que en los cortes clásicos quedaban por delimitar, como la ubicación en la secuencia del mundo de Cogotas I y la definición del Bronce Final.

\section{LA SECUENCIA ESTRATIGRÁFICA DE COSTANILLA TORRE DEL ORO S/N}

La secuencia estratigráfica que nos sirve de base para este estudio fue documentada a finales de 1989 (Fig. 1) durante la excavación realizada por los arqueólogos municipales de Carmona en el solar de la calle Costanilla Torre del Oro s/n de la que ya se ha publicado un informe preliminar (Cardenete y otros, 1989), al que remitimos para la descripción exhaustiva de la secuencia estratigráfica.

El solar donde se realizó la intervención arqueológica está situado al Oeste del casco histórico, intramuros de la ciudad, muy próximo al bastión de la Puerta de Sevilla y a la muralla que se desarrolla hacia el norte.

La secuencia estratigráfica (Fig. 2) abarcaba desde nuestros días hasta el período del Bronce, en una compleja sucesión de 113 Unidades de Estratificación documentadas. En la breve síntesis estratigráfica que vamos a ofrecer, eludiremos las Unidades de Estratificación que no son de interés para los objetivos que nos planteamos, centrándonos en las UUEE. 100 a 113.

La aplicación de principios de descripción e interpretación estratigráficas basados en el método Harris (Harris, 1979, 1991) que constituyen la norma de registro para el equipo arqueológico de Carmona, permiten un análisis minucioso del proceso de estratificación que aseguran una adecuada contextualización de los artefactos y, lo que es más importante, poder interpretar los agentes y procesos que generaron la deposición de las UUEE. a partir de su naturaleza, precisión estratigráfica que hemos echado muy en falta en gran parte de las secuencias analizadas para este trabajo, donde se ha atendido más a los artefactos que a la matriz geológica en la que estaban insertos. El registro primario obtenido por sus excavadores en la intervención arqueológica nos va a servir de base para interpretar los procesos y agentes de la deposición sedimentaria que conforman la secuencia de Costanilla Torre del Oro s/n.

Directamente sobre las calcarenitas se depositó la UE. 113 que debe su origen a la descomposición de la roca terciaria de base, fundamentalmente por la acción del agua que disuelve los componentes calizos generando las arcillas rojas tan características de los suelos de Los Alcores, y por la intervención de procesos coluviales. En este contexto, las cerámicas encontradas muestran un alto índice de rodamiento debido a los procesos que generaron su deposición última. La UE. 111, formada por las arcillas rojas de descomposición del alcor, fue depositada por el arrastre de estas arcillas desde zonas superiores. En esta capa empiezan a encontrarse de una forma más abundante, aunque escasa, vestigios de actividad humana que llegaron a formar parte de esta unidad por arrastre dado el desgaste generalizado que presentan en toda su superficie. La superficie 105 supone el primer nivel, no alterado por procesos naturales, de asentamiento humano. Desde esta superficie se realizan los trabajos de excavación de las unidades 108 y 110, que funcionalmente las tipificamos como silos por las características de deposición de las unidades que la colmataban, por sus dimensiones parciales obtenidas y por la forma acampanada tan características de los silos prehistóricos. La unidad 108 apareció colmatada por las UUEE. 106 y 107. La 107 se formó en un proceso continuo y rápido de deposición de origen claramente antrópico; su naturaleza, determinada fundamentalmente por la abundancia de elementos óseos y cenizas y por su color oscuro, gris-negro, se debía a la descomposición de materia orgánica además de algunos elementos constructivos como son los adobes. Todo esto parece indicar que tras su posible funcionalidad de silo actuó como "basurero". La UE. 106 presentaba unas características distintas, formada principalmente por adobes y piedras, parece que su función era la de cerrar el basurero sellándolo completa- 
mente. Las UUEE. 109 y 110 se documentaron en uno de los perfiles debido a que habían sido parcialmente destruidas por la UE. 25 (correspondiente a la excavación de un pozo de agua de cronología moderna que afectó a toda la secuencia estratigráfica), aunque no se pudieran excavar, las características documentadas tanto en el perfil como en la planta final mostraban una gran similitud con las del silo parcialmente excavado (UUEE. 106-108).

Tras caer en desuso las estructuras citadas y ser totalmente colmatadas se depone sobre ellas la UE. 104, de color rojizo por estar principalmente compuesta por las arcillas propias de la descomposición de la roca terciaria. Entre los materiales que contenía destacaba la presencia muy escasa de fragmentos cerámicos de pequeño tamaño algunos de ellos con evidentes muestras de erosión superficial intensa, lo que hace pensar que la formación de la UE. 104 fue debida a causas naturales de erosión-deposición. La UE. 104 refleja un período cronológico en el que no se detecta la acción antrópica como generadora de estratigrafía y delimita claramente las unidades subyacentes de las superiores estratigráfica y cronológicamente.

La unidad 103 es la cota de superficie a partir de la que se reinaugura la actividad humana. Las UUEE. 100-102 presentan unas características homogéneas con una composición principalmente orgánica, de origen claramente humano. Son capas de escasa potencia de color muy oscuro, casi negro, con abundante presencia de carbón y restos de adobes.

Las UUEE. 98-94, que no analizaremos en este estudio por encuadrarse cronológicamente en el Hierro I, muestran una composición similar donde destacan la presencia de adobes que seguramente dieron el color a la capa. No se encontraron evidencias de estructuras habitacionales pero sí la presencia de una concentración de piedras de diversos tamaños, sin formar estructura, que podría estar relacionada con la cercanía de la muralla protohistórica. La UE. 92 corresponde a un hogar rodeado de adobes que es la única estructura humana localizada entre las UUEE. 102 a 87 aunque no podemos saber si se encontraba al aire libre o en el interior de alguna vivienda al no documentarse restos de muros ni de pavimentos que así lo indicaran, características que comparten las UUEE. 91 y 89.

\subsection{Características descriptivas y tipológicas de los artefactos}

Las UUEE. analizadas, tanto por su naturaleza como por su composición artefactual, pueden agruparse en tres bloques bien definidos. El primero, estaría representado por las UUEE. 100 y 102, que, como veremos a continuación, puede encuadrarse en el Bronce Final. El segundo corresponde a las UUEE. 106 a 110, y, el tercero a las UUEE., 111 a 113, que, aunque de origen no antrópico, contuvieron artefactos que proporcionan un término ante quem para fechar la base de la estratigrafía.

\subsubsection{Unidades de Estratificación 100 y 102}

Los artefactos cerámicos de estas unidades se caracterizan por la ausencia de decoraciones bruñidas y pintadas del tipo Carambolo, una sensible disminución de las formas abiertas y carenadas, y predominio de tipos que se mantendrán durante el primer Hierro, representado en la secuencia por las UUEE. 98 a 89.

De cerámicas decoradas sólo se han recuperado cuatro fragmentos. El primero (Cto 242, fig. 3:12) aparece decorado con incisiones a peine en su cara externa que tiene sus paralelos más cercanos en el nivel 7 del CA80/B fechado a mitad del siglo VIII a.C. (Pellicer y Amores, 1985: fig. 48:10). El segundo, de la UE. 102, (Cto 248, fig. 4:4), es un pequeño fragmento de cuerpo pintado de rojo por ambas caras, cuya forma o motivos no podemos definir. Este tipo de decoración está muy extendida y resulta poco definitoria para caracterizar la 
cultura material de un grupo concreto. También de la UE. 102, se recuperó una pequeña pieza de cuerpo que presenta en su superficie externa dos puntos rellenos de pasta blanca (Cto 260, fig. 4:11). El tipo de decoración nos acerca a ambientes que otros autores llaman Bronce Tardío; su tamaño y posición estratigráfica nos hace pensar que es un fragmento fuera de su unidad matriz. La deposición última de este fragmento, al igual que todos los de la UE. 104, se deben a procesos naturales de erosión y deposición y no a causas antrópicas. El cuarto es un fragmento decorado con ungulaciones en el borde. Prototipos para esta forma los encontramos a lo largo de todo el Bronce, siendo muy frecuentes en el Bronce Tardío caracterizado en el sureste (Molina y Pareja, 1975: fig. 66:266-267), y también en contextos de Bronce Final (Bandera y otros, 1993: fig. 6:14).

Entre las formas más destacadas tenemos el gran cuenco hemisférico de borde engrosado del que contamos con dos ejemplos. La pieza Cto 235 (fig. 3:1) presenta un diámetro de boca de $38,4 \mathrm{cms}$. El borde aparece engrosado al interior y al exterior se señala con una suave inflexión que no llega a destacar como línea de carenación. De la UE. 102 es la pieza Cto 285 (fig. 4:1). Su diámetro de boca es de $26 \mathrm{cms}$., de forma hemisférica, presenta el borde muy engrosado al interior. Tipos muy similares los encontramos en el nivel 11 del CA-80/B en Carmona fechado en el siglo X a.C. (Pellicer y Amores, 1985: fig. 45:9).

Otra de las formas más significativas es el vaso bicónico. El ejemplar Cto 223 (fig. 3:7) presenta el borde redondeado y engrosado al exterior, un diámetro de boca de $16 \mathrm{cms}$. y un acabado exterior bruñido. Este tipo es muy común en contextos de Bronce Final, aparecen en el corte 3 de Setefilla en el estrato XIII (Aubet y otros, 1983: figs. 22:43 y 23:45 y 46), fechable a finales del II milenio a.C. En la misma Setefilla, formas similares fueron utilizadas como urnas cinerarias en la necrópolis (Aubet, 1975: 138-139) ya de época Orientalizante.

El resto de las formas representadas por los fragmentos de este grupo de UUEE. son menos significativas. Destaca la cazuela de carena alta de borde recto y ligeramente entrante, Cto 236 (fig. 3:6) y el cuenco de perfil en S Cto 230 (fig. 3:3). El cuello de "botella" Cto 244 (fig. 4:6) tiene sus paralelos más cercanos en las UE. 107 de nuestro corte (figs. 10:3, 9 y 11) y en el estrato III de El Berrueco de Medina Sidonia (Escacena y Frutos, 1985: fig. 18:97) fechado en el Bronce Tardío (Escacena y Belén, 1991: 20-21).

Resumiendo, las UUEE. 100-102 contienen un conjunto de materiales mayoritariamente compuesto por formas típicas del Bronce Final, junto a otras fragmentos, de muy pequeño tamaño, emparentables con el contexto de las UUEE. 106 y 107 que entendemos no corresponden al bagaje de un mismo grupo, sino que el hecho de que aparezcan juntas se debe a una mezcla con materiales del substrato estratigráfico. Los tipos del Bronce Final, definidos en la secuencia de Costanilla de Torre del Oro, nos acercan a una caracterización en la que están ausentes los tipos guía que han sido indicativos tradicionalmente del Bronce Final tartésico, la retícula bruñida y las pintadas tipo Carambolo, y cuyos paralelos encontramos normalmente en contextos denominados como precoloniales.

\subsubsection{Unidades de Estratificación 106, 107 y 109}

El conjunto cerámico facilitado por este grupo de unidades de estratificación (106, 107 y 109), presenta unas peculiaridades tipológicas que permiten diferenciarlo con claridad de los conjuntos del resto de los grupos de unidades. Esta diferenciación queda plasmada en los tipos que podemos extraer de los fragmentos recuperados.

\section{Formas abiertas.}

Entre las formas abiertas podemos establecer tres tipos característicos: 
1) Las cazuelas carenadas se caracterizan en esta fase por presentar carena hacia la mitad del vaso muy marcada, dando lugar a una forma de tendencia bitroncocónica. Dentro del tipo se destacan diversas variantes tanto en las dimensiones de los vasos, cuyos diámetros de boca oscilan entre los $26 \mathrm{cms}$. de Cto 362 (fig. 7:1) y los 16 de las piezas Cto 366 y 437 (figs. 7:4 y 6), como en los tipos de bordes que se presentan generalmente ligeramente engrosados al exterior (Cto 409, 437 y 355, figs. 7:3, 6 y 7), sin engrosar y ligeramente redondeados (Cto 362 y 366, figs. 7:1 y 4), o muy engrosados tanto al interior como al exterior (Cto 363, fig. 7:2).

Paralelos para esta forma encontramos en el estrato III de El Berrueco de Medina Sidonia (Escacena y Frutos, 1985: fig. 23:143), en un contexto asimilable al Bronce Tardío de Andalucía Oriental (Escacena y Belén, 1991: 20). Una forma idéntica a nuestra Cto 366 (fig. 7:4) aparece en el Bronce Tardío de Fuente Alamo (Arteaga y Schubart, 1980: fig. 14:i) y en el estrato VI/sur de La Cuesta del Negro (Molina y Pareja, 1975: fig. 85:373).

2) Los cuencos hemiesféricos están prácticamente ausentes y contamos únicamente con dos ejemplares (Cto 371 y 404, figs. 7:8 y 9). Entre los cuencos hay que destacar la pieza 376 (fig. 9:4), de cuerpo troncocónico invertido, un diámetro de boca de $14 \mathrm{cms}$. y una altura estimada en torno a los 6-7 cms., de factura poco cuidada y acabado interior y exterior alisado. Esta forma es muy común en contextos del Bronce Medio de la Meseta, en concreto en los Tolmos de Caracena (Jimeno y Fernández Moreno, 1991: figs. 14 a 20), datables en el s. XV a.C.

3) Las fuentes carenadas se caracterizan por tener un diámetro de boca en torno a los $40 \mathrm{cms}$. y una altura que oscila entre $1 / 4$ y $1 / 5$ del diámetro de boca. El borde es recto, vertical o inclinado tanto al exterior como al interior, apuntado o levemente redondeado; el cuerpo aparece de forma de cuarto de esfera o recto en forma de tronco de cono; la base plana (figs. 6:1, 2, 3 y 4).

Tipos similares son muy abundantes en yacimientos de Andalucía Oriental en contextos del Bronce Tardío, en el estrato III/Sur de La Cuesta del Negro (Purullena, Granada) (Molina y Pareja, 1975: fig. 57:217) y en Fuente Alamo (Arteaga y Schubart, 1980: fig. 14g).

Podemos considerar una variante de esta forma el tipo representado en nuestra fig. 11:1 (Cto 410), dejando de lado su decoración que ya analizaremos más adelante, que presenta un cuerpo troncocónico y mayor altura que las que hasta ahora hemos descrito y fondo destacado; el borde vertical se destaca del cuerpo por una pronunciada carena. Este tipo los encontramos en contextos de Cogotas I en la Meseta y en el Bronce Tardío de Andalucía Oriental, convirtiéndose en uno de los más característicos que definen esta cultura. En La Cuesta del Negro lo hallamos en el estrato III/norte y IV/norte, normalmente decorada (Molina y Pareja, 1975: figs. 27:77 y 30:99).

\section{Formas cerradas}

1) El pequeño vaso ovoide Cto 292 (fig. 5:8) refleja una forma muy común en los conjuntos asimilables a Cogotas I. Este pequeño vaso posee un diámetro de boca de $7 \mathrm{cms}$. y una altura de las mismas dimensiones; el cuerpo tiene tendencia ovoide o bicónica marcada por una suave inflexión en la mitad del vaso; carece de asiento estable al tener una base redondeada. Un vaso de similares características lo encontramos en el estrato V/sur de La Cuesta del Negro (Purullena, Granada) (Molina y Pareja, 1975: fig. 70:283), aunque de dimensiones ligeramente más reducidas que nuestro ejemplar.

Dentro de esta forma incluimos también la pieza Cto 359 (fig. 11:3) que carece de la inflexión que presenta el vaso antes descrito. Su diámetro de boca es de $9,5 \mathrm{cms}$. y su altura estimada en torno a los $7 \mathrm{cms}$.; el cuerpo es ovoide, el borde está ligeramente inclinado al interior y el labio engrosado al exterior.

Los vasitos ovoides son característicos de los complejos Cogotas I de la Meseta y aparecen en yacimientos como Las Carretas (Casaseca de las Chanas, Zamora) o El Berrueco (Salamanca) (Fernández-Posse, 1982: figs. $2: 4,7$ y 8 ). 
2) Las orzas ofrecen una relativa variedad en cuanto a formas y tamaños que podemos sintetizar en los siguientes tipos:

2.1) Orzas de pared vertical. Son vasos de cuerpo con tendencia fundamentalmente cilíndrica o troncocónica, aunque también se presentan con forma globular (Cto 352, fig. 8:1), cuyo diámetro de boca oscila entre los $12 \mathrm{cms}$. de la pieza 429 (fig. 9:6) y los $18 \mathrm{cms}$. de las 405 y 352.

El tratamiento exterior suele ser alisado y las pastas no muy depuradas. Dentro del tipo genérico se pueden establecer distinciones en función de la morfología del labio, que aparece ligeramente engrosado (Cto 375, fig. 9:3), plano (406, 429 y 431, figs. 9:1, 6 y 8), redondeado (Cto 407 y 352, figs. 9:12 y 8:1) o vuelto al exterior (Cto 367, fig. 9:2).

Los sistemas de sustentación habituales son los mamelones en el borde (Cto 429 y 407, figs. 9:6 y 12), algunas veces perforados (Cto 367, fig. 9:2), y las perforaciones (Cto 375, fig. 9:3).

Este tipo es característico de ambientes Cogotas I y es en el yacimiento de la Cuesta del Negro (Purullena, Granada) donde están ampliamente representadas en todas sus variantes. Las de paredes verticales y borde simple se constatan en los estratos IV/sur (Molina y Pareja, 1975: figs. 66:264-267), V/sur (figs. 75:312 y 313) y VI/sur (figs. 95:415).

2.2) Orzas de pared inclinada al interior. Se caracterizan por tener un cuerpo de tendencia troncocónica o globular, un diámetro de boca que oscila entre los $11 \mathrm{cms}$. (Cto 288, fig. 5:4) y los 23,5 cms de la pieza 393 (fig. 8:3). El tratamiento exterior es fundamentalmente alisado y las pastas poco depuradas. Los bordes se presentan con las mismas características apuntadas para las orzas de borde vertical, de labio engrosado (Cto 369 y 290, figs. 8:2 y 5:2), de labio apuntado (Cto 288, fig. 5:4) o vuelto al exterior (Cto 307 y 393, figs. 5:3 y $8: 3$ ).

Las orzas de paredes entrantes aparecen en los estratos IV/norte, IV/sur, V/sur y VI/sur, con los bordes apuntados, engrosados o vueltos al exterior (Molina y Pareja, 1975: figs. 35:133, 65:262-263, 75:309, 91:399$404,93,94: 413,96: 416,97,98,99$ y 100:440). En Fuente Alamo encontramos este tipo como en el caso de la figura 13 a (Arteaga y Schubart, 1980) que es una orza de paredes entrantes con el borde vuelto al exterior, que en este ejemplar presenta decoración.

3) Al tipo de ollas globulares corresponde el vaso Cto 440 (fig. 13:2) de la UE. 109. Su factura es poco cuidada, tratamiento exterior e interior alisado, sus dimensiones son de $25 \mathrm{cms}$. de diámetro de boca y una altura aproximada de $15 \mathrm{cms}$. Las huellas externas de fuego parecen evidenciar su funcionalidad de olla.

\section{Técnicas y motivos decorativos}

Digitaciones. La técnica decorativa a base de impresiones con los dedos está representada por un único ejemplar, Cto 438 (fig. 13:4), que presenta digitaciones tanto en el borde como en el resto de la superficie exterior del vaso. Este tipo de decoración está presente de manera significativa en contextos del Bronce Tardío de Andalucía Oriental, en Fuente Alamo (Arteaga y Schubart, 1980: fig. 13-F) y en el estrato IV/sur de La Cuesta del Negro (Molina y Pareja, 1975: figs. 92:405, 406 y 407).

Cordones digitados. La decoración con cordones digitados está documentada en la pieza Cto 288 de la UE. 106 (fig. 5:4). Se trata de un fragmento de borde y cuerpo perteneciente a un vaso cerrado y que presenta un cordón de escaso volumen en la cara externa del borde decorado con impresiones digitales de pequeño tamaño.

Técnicas de incrustación. En este apartado incluimos la incisión, el puntillado y el boquique, técnicas que suelen aparecer juntas en un mismo vaso y que normalmente se rellenan con pasta blanca, por lo que el aspecto final del vaso no permitiría distinguir si la técnica empleada es la incisión o el boquique, por ello creemos, siguiendo a Maluquer (1956: 188), más importante los motivos decorativos generados que la técnica.

Entre los motivos el más importante sin duda es el de semicírculos concéntricos o guirnaldas que se repiten 
reiterada y monótonamente en la mayoría de los vasos decorados, formados tanto en técnica de boquique como incisa y sobre vasos de distintas tipologías.

El vaso Cto 410 (fig. 11:1) es una fuente de cuerpo troncocónico como ya hemos indicado. Al exterior, el esquema compositivo de la decoración presenta una clara delimitación entre el borde y el cuerpo. El borde se decora con una línea incisa bajo el labio y otra marcando la inflexión con el cuerpo dejando el resto en reserva. El cuerpo se decora, a partir de la línea incisa que delimita la carena, con series de semicírculos concéntricos realizados con técnica incisa que dejan entre sí poco espacio. De las tres series que conserva el vaso, la central está compuesta por seis líneas mientras que las laterales, que parten desde el semicírculo más excéntrico de la serie central, están compuestas de ocho líneas. El resto del cuerpo hasta la base estaría sin decorar. El interior del labio se decora con una serie de zig-zag discontinuo a base de impresiones husiformes. Todos los motivos decorativos irían rellenos de pasta blanca, que se conserva en algunas zonas, lo que haría destacar la decoración sobre el fondo negro intensamente bruñido.

Un aspecto compositivo similar muestra la pieza Cto 321 (fig. 11:2), un vaso de perfil en $S$ y base realzada. Al exterior, se marca el final del labio con tres líneas incisas horizontales y paralelas, y la transición cuello/ cuerpo con otra línea incisa. El cuerpo se decora con líneas, realizadas con técnica incisa, formando guirnaldas que delimitan entre sí una serie de bandas que se rellenan alternativamente con puntillado.

El pequeño vaso Cto 359 (fig. 11:3) está decorado únicamente al exterior. Se marca el final del labio con una línea incisa, bajo ella, una línea de boquique formando una guirnalda, sirve de partida para series de semicírculos concéntricos realizados en técnica de boquique.

El resto de los ejemplares recuperados decorados con técnica de incrustación no permiten reconstruir los esquemas compositivos de los vasos a los que pertenecerían. Los fragmentos 343 , 324 y 325 pertenecen con seguridad a un mismo vaso y posiblemente también lo sean las piezas 416 y 357 (figs. 12:1, 2, 3, 4 y 5). Se trata de un vaso cerrado de forma posiblemente globular, decorado al exterior con líneas horizontales y guirnaldas realizadas con técnica de boquique. Motivos distintos a los expuestos hasta ahora nos muestran los fragmentos 291 (fig. 5:5) y 447 (fig. 12:7). El primero de ellos es un triángulo realizado con técnica de boquique relleno de puntillado, el segundo representa una serie de metopas realizadas con técnica incisa y rellenas alternativamente de puntillado.

Los motivos, técnicas y esquemas compositivos descritos son característicos de los complejos tipológicos Cogotas I, lo que haría interminable (e innecesario) la relación de paralelos concretos para cada uno de los motivos.

\section{Utiles óseos y líticos}

El repertorio material lítico y óseo recuperado es muy escaso y el metálico es inexistente.

Entre la industria lítica es muy pobre reseñando la pieza Cto 507 (fig. 6:6), un raspador sobre el extremo distal de una lámina, del que se conserva la punta del útil. La fig. 6:7 (Cto 506) es un fragmento de lámina con retoque marginal y distal simple. Un perforador en cuarcita, de sección triédrica y retoque marginal simple, con fractura en la punta, está representado en nuestra fig. $6: 8$ (Cto 510). La pieza Cto 511, (fig. 6:5) es un canto plano con dos series de muescas laterales opuestas que estrangulan la pieza de difícil adscripción funcional. Tipos similares encontramos en la cueva de Boquique con 28 ejemplares que se interpretaron como pesas de red (Rivero, 1972-73: figs. 5-7). La misma interpretación se dio a una pieza similar aparecida en la prospección del yacimiento de Sierra de la Lapa en la provincia de Huelva, en un contexto del Bronce Final (Pérez Macías, 1983: 213). Almagro Gorbea (1977: 108) indica que la abundancia con que aparecen en los poblados podría indicar su uso como pesas de telar. En Carmona, durante la excavación del corte CA-80/A, se extrajo un canto rodado de idénticas características en el fondo de un silo encuadrado en un horizonte eneolítico (Pellicer y Amores, 1985: fig. 13:11). 
El último elemento a destacar es un fragmento de punzón de hueso (Cto 508, fig. 6:9), único testimonio de industria ósea recuperado.

\subsubsection{Unidades de Estratificación 111 y 113}

Los materiales que incluimos en este grupo corresponden a las UUEE. de base de la estratigrafía (111 y 113). La adscripción cultural resulta difícil por el escaso número de fragmentos cerámicos recuperados y, ante todo por el estado en que se encuentran. Los materiales aparecen muy rodados hasta el punto que han perdido, en muchos de ellos, la superficie original por lo que incluso su orientación resulta compleja.

Entre los fragmentos recuperados, el más significativo, es el Cto 284 (fig. 14:6). Se trata de una fuente carenada de borde recto, plano y engrosado al exterior, con mamelón perforado en la línea de carenación y acabado interior y exterior bruñido. El diámetro de boca está en torno a los $30 \mathrm{cms}$.

\subsection{Cronología}

Otorgar unos valores temporales absolutos a la formación de las UUEE. documentadas en Costanilla Torre del Oro $\mathrm{s} / \mathrm{n}$, no resulta fácil al no contar con apoyos en dataciones de $\mathrm{C}_{14^{1}}$. Por tanto, las bases para la asignación cronológica se van a centrar en la secuencia relativa obtenida de la interpretación estratigráfica y en el repertorio tipológico de los materiales que formaban parte de dichas unidades de estratificación.

Estos dos elementos creemos que son lo suficientemente significativos como para establecer una seriación cronológica ajustada y coherente. La secuencia estratigráfica, que ya hemos tratado, está compuesta de unas UUEE. cuya caracterización ofrece datos claros sobre su origen y proceso de formación, que servirá de puntal al esquema cronológico que proponemos. Por otro lado, los conjuntos tipológicos son paralelizables con conjuntos de otros yacimientos que sí poseen dataciones absolutas, y su similitud no nos deja duda de extrapolar esos valores cronológicos a la formación de nuestras UUEE.

Las UUEE. 100 y 102 poseen una escasa potencia, un color negruzco, que evidencia la presencia de carbón y materia orgánica, y unos materiales que, emparentables en formas y tratamientos con los de las UUEE. del Hierro I, presentan rasgos distintos entre los que destacan la ausencia de la técnica de decoración bruñida y pintada de tipo Carambolo. Los paralelos para este conjunto los encontramos en la base de los estratos con conjuntos del Bronce Final "típico" bajoandaluz, nivel 11 del CA-80/B (Pellicer y Amores, 1985: fig. 45), parte superior del estrato 5 del Raso de Santa Ana (Carriazo y Raddatz, 1960: fig. 12:1-8, 12 y 14), en el estrato XIII de Setefilla (Aubet y otros, 1983: figs. 22 y 23), el estrato V del Berrueco de Medina Sidonia (Escacena y Frutos, 1985: figs. 28, 29 y 30) y en la denominada fase Ia de Montemolín (Bandera y Chaves, 1993: fig. 4). Creemos, por tanto, que estos materiales reflejan los momentos precoloniales que con tanto empeño se han intentado aislar en los últimos años, y con una cronología imprecisa que debe estar centrada en los siglos IX y primera mitad del VIII a.C. La poca potencia de estas UUEE. ha provocado la presencia de muchos fragmentos de cerámica ajenos a la cultura generadora de dichas unidades y que son fácilmente reconocibles por las pequeñas dimensiones de los mismos y las huellas de desgaste que presentan (figs 4:2, 4, $7,8,9,10,11$ y 13$)$.

El grupo de UUEE. 106 a 110 aporta un conjunto cerámico lo suficientemente característico como para

1. Se extrajo una muestra de carbón de la UE 107 y estamos a la espera de poder analizarla. 
que su adscripción cultural y cronológica no ofrezca dudas, a pesar de no contar con el apoyo de sistemas de datación absoluta. Resumiendo, el repertorio cerámico ofrecido por las UUEE. 106 y 107 es idéntico, tanto en las cerámicas decoradas, las que hasta ahora más atención han recibido, como en los tipos no decorados, a los conjuntos del Bronce Tardío de Andalucía Oriental, por lo que no consideramos descabellado asignar el mismo margen cronológico establecido para el Bronce Tardío.

La cronología asignada a los conjuntos emparentados a Cogotas I en Andalucía Oriental ha evolucionado desde una primera adscripción al Bronce Final, entre el siglo $X$ y la primera mitad del siglo IX a.C. (Molina y Pareja, 1975: 56), hasta encuadrarse, con el soporte de las fechas de $C_{14}$, en el último tercio del II milenio en un período que acabó por llamársele Bronce Tardío (Molina, 1978: 201; Molina y Arteaga, 1975: 187). Las fechas obtenidas en Fuente Alamo para los contextos del Bronce Tardío oscilan entre el 1450 \pm 50 a.C. (FA690) y $1210 \pm 90$ a.C. (FA-644) ofreciendo un marco cronológico entre el 1400 y el 1100 a.C. (Schubart y Arteaga, 1986: 292). Para el yacimiento de La Cuesta del Negro (Purullena, Granada) contamos con dos dataciones que fechan el momento de construcción y abandono de la última de las cuatro cabañas superpuestas de Cogotas I, $1210 \pm 35$ y $1145 \pm 35$ a.C. respectivamente (Molina, 1978: 170). Estas dataciones ofrecen como punto de partida para el Bronce Tardío, el final de la cultura argárica y un final en torno al 1100 a.C. La fecha actualmente aceptada para el desarrollo de esta cultura en Andalucía Oriental oscila entre el 1300 y el 1100 a.C. (Arteaga, 1982: 137), cronología que concuerda con la mayor parte de las dataciones radiocarbónicas obtenidas en la Península para contextos de Cogotas I (Delibes y Fernández-Miranda, 1986-87: 23). Por todo esto, nosotros proponemos que las UUEE. 106 a 110 se formaron en un momento entre el 1400 y el 1100 a.C.

La datación del último grupo de UUEE. es más compleja e imprecisa. La UE. 113, originada por la descomposición de la roca de base, refleja el proceso de formación de los suelos rojos de Los Alcores, que comenzaría tras el afloramiento de las calcarenitas. La UE. 111 se formó por procesos de deposición de tipo coluvial. Entre los materiales cerámicos que contenía, destaca una gran fuente carenada (Cto 284, fig. 14:6) que, por los paralelos asignados parece corresponder al mundo de las fuentes (o cazuelas) carenadas de la primera fase del Calcolítico, por lo que su formación fue lenta y continuada desde el Calcolítico hasta el asentamiento de los grupos de Cogotas I.

Una proceso de formación similar tuvo la UE. 104, compuesta de tierras rojizas y fragmentos de cerámica de pequeño tamaño y con muestras de rodamiento lo que, como ya hemos indicado, muestran un carácter no antrópico para la formación de la UE. La importancia de esta capa radica en que separa física y cronológicamente a las UUEE. pertenecientes al Bronce Final (100-102) de las 106-110, cuya deposición hemos calculado en torno a los siglos XIV-XII a.C. La UE. 104 representa, al menos en lo reflejado en la estratigrafía, una interrupción de la acción antrópica en el lugar, un hiato que, en función de las dataciones propuestas para las UUEE. que delimitan la UE. 104, iría desde el siglo XI al IX a.C.

\section{SECUENCIA CRONOLÓGICA Y ESTRATIGRÁFICA DEL FINAL DEL BRONCE}

La información proporcionada por esta nueva estratigrafía permite aportar nuevos datos para establecer la secuencia cultural de los últimos momentos del Bronce, que ayudan a despejar ciertas dudas que los cortes del Raso de Santa Ana, CA-80/A y CA-80/B habían dado lugar.

La secuencia estratigráfica de origen antrópico se inaugura con la excavación de los silos UE. 108 y UE. 110 sobre un sustrato de formación natural que contenía restos muy rodados de cerámicas que pudieran reflejar un poblamiento anterior, quizás datable en el Calcolítico. La misma naturaleza de estas capas muestran un largo período cronológico en el que actuaron los agentes naturales antes de la reocupación de la zona por los grupos emparentados con Cogotas I. La caracterización de los artefactos recuperados en el interior de los silos 
ha permitido, por primera vez en el yacimiento, contextualizar adecuadamente la cerámica de boquique que tanto se prodiga en Carmona y despejar las incertidumbres que sobre su ubicación en la secuencia se han planteado en múltiples trabajos. Las cerámicas de boquique aparecen en contextos de muy similares características que en el denominado Bronce Tardío en Andalucía Oriental y ocupando su mismo lugar en la secuencia.

Sobre la colmatación de los silos se depuso la UE. 104 cuya formación por agentes naturales evidencia físicamente una separación cronológica y estratigráfica con las UUEE. pertenecientes al Bronce Final. Los artefactos que contenía son piezas de muy pequeño tamaño y con intensa erosión superficial, lo que muestra que han sido extraídos de su matriz y sufrido un proceso de fragmentación y erosión antes de su deposición última.

La posterior reocupación (UUEE. 102-100) se produce por grupos con un bagaje absolutamente diferente a los que formaron las UUEE. 106-110, y que cronológicamente se sitúan ya en el primer milenio a.C. La presencia de fragmentos de pequeño tamaño, que por su decoración se pueden emparentar con los tipos de Cogotas I, no es más que el reflejo de la inclusión de piezas del sustrato al reocupar la zona.

Los resultados expuestos nos hacen dudar de la perduración de los elementos Cogotas I hasta el Bronce Final2 $^{2}$, como se ha interpretado (Pellicer y Amores 1985: 181; Pellicer, 1987-88; Amores y Rodríguez Hidalgo, 1984-85: 85; Bandera y otros, 1993: 24) y, también, que convivan con conjuntos campaniformes (cf Bandera y otros, 1993:24), hecho que podemos contrastar analizando las descripciones estratigráficas que hicieron los autores en el Raso de Santa Ana y en el CA-80/A y B.

La excavación que practicaron Raddatz y Carriazo en 1959 (1960), se realizó en una zona donde el desprendimiento continuado de las laderas del yacimiento dejaba al descubierto un perfil estratigráfico que ayudó a los arqueólogos a elegir el lugar más idóneo para sus expectativas. Este hecho les permitía, además, tener una visión global de toda la estratigrafía previa a la excavación, lo que en cierta medida disminuía las posibilidades de errores en la interpretación estratigráfica. No obstante, la definición de los estratos que hicieron los autores restó precisión a la secuencia.

El estrato 5 "se sobreponía sin clara delimitación al estrato castaño de disgregación de la superficie de la roca terciaria". El estrato 5, en la figura 2, incluye el estrato castaño de base representado en la figura 1 con tramado distinto. Esta división interna está acentuada por una distinción en los materiales. Los escasos fragmentos decorados se situaban en la base del estrato, por lo que "quizá la cerámica decorada corresponda al hábitat más antiguo, mientras que la lisa correspondería a una fase posterior" (1960: 358).

El corte CA-80/A, efectuado por Pellicer y Amores en 1980 (1985), se situó muy cerca de donde años antes habían intervenido Carriazo y Raddatz y tenía como finalidad contrastar aquella primera estratigrafía (Pellicer y Amores, 1985: 65). La secuencia obtenida es paralela a la de 1959 y sus resultados comparables en todo su desarrollo. Los autores consideran que el CA-80/A no se correspondía exactamente al de 1959 ya que no se pudo constatar el estrato precolonial (Pellicer y Amores, 1985: 65). La actuación humana durante el período Orientalizante incide directamente sobre la roca de base afectando a las estructuras preexistentes, lo que explicaría la ausencia de estratificación paralela a la de la parte superior del estrato 5 del corte de 1959, evidenciado por la presencia de fragmentos con decoración de boquique en niveles ajenos a los de su cultura formativa (Pellicer y Amores, 1985: fig. 36-6, fgto. 1398 perteneciente al nivel 21A). La estructura troncocónica apareció colmatada en su parte inferior por materiales prehistóricos que los autores fechan en el Calcolítico, pero dada la indefinición de los mismos dicha adscripción no parece segura.

El CA-80/B se situó en la zona del Picacho, en el límite opuesto al que se situó el CA-80/A, donde los

2. Entendemos por Bronce Final la etapa precolonial de la cultura tartésica. Los límites cronológicos y estratigráficos que asignamos al mundo de Cogotas I en Carmona nos hacen incluirlo en un Bronce Tardío o, mejor, en un Bronce Medio abarcando este período la segunda mitad del II milenio a.C. 
hallazgos superficiales y el perfil dejado por los sucesivos desplomes del acantilado mostraba la posibilidad de "poder realizar trabajos arqueológicos sobre Calcolítico, Bronce Pleno y Bronce Final...casi desde superficie" (Pellicer y Amores, 1985: 99). Se documentaron un total de 13 niveles agrupados en 6 estratos. A partir del nivel 5 comienzan las capas del Bronce Final representado por los niveles 6-10. Los niveles 5 y 6 correspondían respectivamente al derrumbe e interior de una cabaña, que apareció delimitada por un muro de adobes. Los niveles 7 y 8 correspondían a una fase previa de habitación constatada por la presencia de otro pavimento aunque sin relación con ninguna estructura que lo cerrara. Los niveles 9 y 10 componían una capa de características distintas a las precedentes con escaso material. Los niveles 11 a 13 formaban la base de la estratigrafía (Pellicer y Amores, 1985: 100-103). Las dataciones propuestas por los autores hacen corresponder los niveles 13 a 6 a "un Calcolítico y Bronce Pleno muy difuso ya en Bronce Final, siendo los restantes, del 5 al 4 de horizontes posteriores...", con una datación desde fines del $2^{\circ}$ milenio hasta en torno al 700 a.C. para el momento precolonial y a partir de esa fecha para el resto (Pellicer y Amores, 1985: 180).

A partir de la información expuesta por los autores creemos necesario hacer unas puntualizaciones, tanto sobre la interpretación de la estratigrafía como de la datación propuesta a partir de los nuevos datos aportados sobre la secuencia poblacional y la naturaleza de la estratificación. Los niveles 12 y 13 tienen su origen en procesos de erosión/deposición de las arcillas rojas producto de la descomposición de la roca de base, por ello no corresponden a un nivel de habitación. Entre los materiales correspondientes a estos niveles destacan los fragmentos con decoración campaniforme (1985: fig. 44, 7, 8, 9 y 10) junto a otros que tipológicamente pudieran pertenecer a un Bronce Inicial (1985: fig. 44, 2 y 4). Su proceso de formación concluyó con la deposición del nivel 11, ya de claro origen antrópico, por lo que, a partir de los fragmentos cerámicos que contiene, su formación debió abarcar los períodos Calcolítico y Bronce Inicial hasta el Bronce Medio.

El nivel 11, presenta dos conjuntos tipológicos diferentes. El primero de ellos corresponde a un Bronce Medio por la presencia de fragmentos decorados con técnica de boquique (1985: fig. 45, 15 y 16), y de un plato carenado de pequeño borde entrante a bisel (1985: fig. 45, 10) con paralelos en el estrato III del Berrueco de Medina Sidonia (Escacena y Frutos, 1985: fig. 19-110) fechado por $\mathrm{C}_{14}$ en 1360 a.C. correspondiente a un Bronce Tardío (Belén y Escacena, 1992 y Escacena Belén, 1991: 20-21). De otra parte, un segundo conjunto, directamente emparentado con las UUEE. 100-102 de Cto, presenta como elementos más significativos un fragmento con decoración peinada, un cuenco hemiesférico de borde engrosado al interior y un vaso bicónico de paredes finas (Pellicer y Amores, 1985: figs. 45:14, 9 y 1 resp.).

Con todo, ante la evidencia de que los conjuntos de Cogotas I se infraponen en estas secuencias a los del Bronce Final, podemos sugerir como causa que explique la contextualización de ambos conjuntos el hecho de que la potencia estratigráfica generada en estas etapas es muy escasa, produciendo capas de escasa consistencia y fácilmente erosionables que permite el desarraigo de los artefactos que contuvieron.

La diferenciación de los conjuntos de Cogotas I con respecto a los del Bronce Final tartésico plantea una serie de cuestiones de singular interés para el conocimiento del origen de la cultura tartésica. En primer lugar, parece imposible establecer relaciones de parentesco entre ambos mundos con lo que se quebraría cualquier hipótesis continuista que intentara enlazar el mundo tartésico con el sustrato; además, por lo reflejado en la secuencia de Costanilla Torre del Oro, no existe una suplantación inmediata de los grupos del Bronce Final sobre Cogotas I, sino que existe una separación física (UE. 104) y cronológica entre ambos. La presencia de un hiatus entre los momentos del Bronce Medio y Final en Andalucía Occidental ha sido apuntada recientemente por Belén y Escacena (1992 y Escacena y Belén, 1991) a partir de la revisión de las principales secuencias estratigráficas, hecho que queda reflejado en lo que hemos expuesto. La dimensión cronológica de este hiato la podemos cifrar, a partir de las cronologías que hemos propuesto, en torno a los 200 años. Desconocemos las causas, que provocan este vacío en el registro, ya sean reflejo de una etapa de crisis o de un problema metodológico es algo que tendremos de solventar. 


\section{APÉNDICE}

\section{Materiales de la UE. 100:}

Fig. 3:7. Cto 223. Fragmento de borde y cuerpo, pasta gris y naranja, textura porosa, desgrasante medio, mica y caliza, modelado a mano, cocción reducida; acabado interior alisado, exterior bruñido.

Fig. 3:2. Cto 226. Fragmento de borde y cuerpo, pasta gris y naranja, textura porosa, desgrasante medio, mica y caliza, modelado a mano, cocción reducida; acabado interior alisado, exterior bruñido.

Fig. 3:4. Cto 227. Fragmento de borde, pasta gris, textura porosa, desgrasante fino, calizo, modelado a mano, cocción reducida; acabado interior y exterior bruñido.

Fig. 3:3. Cto 230. Fragmento de borde, cuello y cuerpo, pasta gris y naranja, textura porosa, desgrasante fino, mica y caliza, modelado a mano, cocción reducida; acabado interior y exterior bruñido.

Fig. 3:11. Cto 233. Fragmento de base, pasta roja, textura porosa, desgrasante medio, caliza y cuarzo, modelado a mano, cocción irregular; acabado interior alisado, exterior bruñido.

Fig. 3:9. Cto 234. Fragmento de base, pasta negra y anaranjada, textura porosa, desgrasante medio, arenoso y calizo, modelado a mano, cocción irregular; acabado interior y exterior alisado; marcas externas de fuego.

Fig. 3:1. Cto 235. Fragmento de borde y cuerpo, pasta negra y gris, textura porosa, desgrasante fino, arenoso, modelado a mano, cocción reducida; acabado interior y exterior bruñido.

Fig. 3:6. Cto 236. Fragmento de borde cuello y cuerpo, pasta negra y naranja, textura porosa, desgrasante fino, calizo, modelado a mano, cocción reducida; acabado interior alisado y exterior bruñido; desgaste externo.

Fig. 3:8. Cto 238. Fragmento de borde, pasta negra, textura porosa, desgrasante fino, mica y caliza, modelado a mano, cocción reducida; acabado interior y exterior bruñido.

Fig. 3:5. Cto 239. Fragmento de borde, pasta gris y naranja, textura porosa, desgrasante medio, arenoso y calizo, modelado a mano, cocción reducida; acabado interior y exterior bruñido.

Fig. 3:10. Cto 241. Fragmento de borde y cuello, pasta gris y naranja, textura porosa, desgrasante fino, arenoso y calizo, modelado a mano, cocción reducida; acabado interior alisado, exterior bruñido.

Fig. 3:12. Cto 242. Fragmento de cuerpo, pasta negra y roja, textura porosa, desgrasante medio, mica y caliza, modelado a mano, cocción irregular; acabado exterior sin tratar; decoración externa incisa peinada.

\section{Materiales de la UE. 102:}

Fig. 4:6. Cto 244. Fragmento de borde y cuello, pasta negra, textura porosa, desgrasante fino, arena y cuarzo, modelado a mano, cocción reducida; acabado interior alisado, exterior bruñido.

Fig. 4:10. Cto 245. Fragmento de borde, pasta negra y naranja, textura porosa, desgrasante grueso, mica, caliza y cuarzo, modelado a mano, cocción irregular; acabado interior y exterior alisado.

Fig. 4:9. Cto 247. Fragmento de borde, pasta negra y roja, textura porosa, desgrasante fino, calizo, modelado a mano, cocción reducida; acabado interior y exterior bruñido.

Fig. 4:4. Cto 248. Fragmento de cuerpo, pasta negra, textura porosa, desgrasante medio, arena y cuarzo, modelado a mano, cocción reducida; acabado interior y exterior bruñido; decoración interior y exterior pintada en rojo.

Fig. 4:5. Cto 249. Fragmento de borde y cuello, pasta negra, gris, textura porosa, desgrasante grueso, mica, caliza y cuarzo, modelado a mano, cocción irregular; acabado interior alisado, exterior espatulado:

Fig. 4:2. Cto 250. Fragmento de borde, pasta negra y roja, textura porosa, desgrasante fino, mica y caliza, modelado a mano, cocción irregular; acabado interior alisado, exterior bruñido. 
Fig. 4:13. Cto 252. Fragmento de borde, pasta negra, textura porosa, desgrasante fino, calizo, modelado a mano, cocción reducida; acabado interior y exterior bruñido.

Fig. 4:8. Cto 253. Fragmento de borde, pasta gris y naranja, textura porosa, desgrasante fino, mica y caliza, modelado a mano, cocción reducida; acabado interior y exterior alisado.

Fig. 4:12. Cto 254. Fragmento de base, pasta negra, textura porosa, desgrasante fino, calizo, modelado a mano, cocción reducida; acabado interior y exterior alisado; presenta desgaste en la base.

Fig. 4:7. Cto 255. Fragmento de borde, pasta negra, textura porosa, desgrasante fino, calizo, modelado a mano, cocción reducida; acabado interior y exterior bruñido.

Fig. 4:3. Cto 256. Fragmento de borde, pasta negra, textura porosa, desgrasante fino, mica y caliza, modelado a mano, cocción reducida; acabado interior y exterior bruñido.

Fig. 4:11. Cto 260. Fragmento de cuerpo, pasta negra, textura porosa, desgrasante fino, arenoso y calizo, modelado a mano, cocción reducida; acabado interior y exterior alisado; decoración externa con dos puntos incisos rellenos de pasta blanca.

Fig. 4:1. Cto 285. Fragmento de borde y cuerpo, pasta negra y roja, textura porosa, desgrasante medio, mica y caliza, modelado a mano, cocción irregular; acabado interior bruñido, exterior bruñido y escobillado.

\section{Materiales de la UE. 104:}

Fig. 4:16. Cto 276. Fragmento de base, pasta roja, textura porosa, desgrasante grueso, mica, arena, caliza y cuarzo, modelado a mano, cocción reducida; acabado interior bruñido, exterior alisado; desgaste superficial generalizado.

Fig. 4:17. Cto 277. Fragmento de borde, pasta roja, textura porosa, desgrasante fino, calizo, modelado a mano, cocción irregular; acabado interno y externo bruñido.

Fig. 4:15. Cto 278. Fragmento de borde, pasta negra, textura porosa, desgrasante fino, calizo, modelado a mano, cocción reducida; acabado interior y exterior alisado.

Fig. 4:14. Cto 279. Fragmento de borde, pasta gris y naranja, textura porosa, desgrasante fino, calizo, modelado a mano, cocción irregular; acabado no definible; desgaste superficial generalizado.

\section{Materiales de la UE. 106:}

Fig. 5:6. Cto 287. Fragmento de borde, pasta negra, textura porosa, desgrasante fino, arena y cuarzo, modelado a mano, cocción reducida; acabado interior espatulado, exterior alisado.

Fig. 5:4. Cto 288. Fragmento de borde y cuello, pasta negra y naranja, textura porosa, desgrasante medio, caliza y cuarzo, modelado a mano, cocción irregular; acabado interior alisado, exterior espatulado; decoración exterior plástica, un cordón con digitaciones; marcas externas de fuego.

Fig. 5:1. Cto 289. Fragmento de borde y cuello, pasta negra y roja, textura porosa, desgrasante grueso, mica, caliza y cuarzo, modelado a mano, cocción irregular; acabado interior y exterior alisado; marcas externas de desgaste.

Fig. 5:2. Cto 290. Fragmento de borde, pasta naranja, textura porosa, desgrasante medio, arenoso, modelado a mano, cocción irregular; acabado interior y exterior bruñido.

Fig. 5:5. Cto 291. Fragmento de cuerpo, pasta roja, textura porosa, desgrasante fino, arenoso y calizo, modelado a mano, cocción reducida; acabado interior y exterior alisado; decoración externa línea de boquique delimitando un campo puntillado.

Fig. 5:8. Cto 292. Forma semicompleta, pasta negra y naranja, textura porosa, desgrasante medio, arena, 
caliza y cuarzo, modelado a mano, cocción irregular; acabado interior y exterior alisado; marcas externas fuego y desgaste.

Fig. 5:3. Cto 307. Fragmento de borde y cuello, pasta negra, textura porosa, desgrasante medio, arenoso y calizo, modelado a mano, cocción irregular; acabado interior espatulado, exterior sin tratar; marcas externas fuego e impresiones.

Fig. 5:9. Cto 308. Fragmento de base, pasta negra, textura porosa, desgrasante medio, arenoso y calizo, modelado a mano, cocción irregular; acabado interior y exterior sin tratar; marcas externas fuego, impregnaciones y desgaste.

Fig. 5:2. Cto 310. Forma semicompleta, pasta negra, textura porosa, desgrasante grueso, calizo, modelado a mano, cocción reducida; acabado interior y exterior alisado; marcas externas de fuego.

Fig. 5:2. Cto 321. Forma semicompleta, pasta negra y roja, textura porosa, desgrasante medio, mica, caliza y cuarzo, modelado a mano, cocción irregular; acabado interior y exterior alisado; Decoración exterior incisa, tres líneas paralelas bajo el borde y en el cuerpo un motivo de guirnaldas rellenando alternativamente de puntos incisos las bandas creadas.

Fig. 5:7. Cto 322. Fragmento de borde, pasta negra, textura porosa, desgrasante grueso, arena, caliza y cuarzo, modelado a mano, cocción reducida; acabado interior alisado, exterior bruñido; decoración externa línea incisa bajo el borde.

\section{Materiales de la UE. 107:}

Fig. 6:2. Cto 310. Forma semicompleta, pasta negra, textura porosa, desgrasante grueso, calizo, modelado a mano, cocción reducida; acabado interior y exterior alisado; marcas externas de fuego.

Fig. 12:2. Cto 324. Fragmento de cuerpo, pasta negra, textura porosa, desgrasante fino, arenoso y calizo, modelado a mano, cocción reducida; acabado interior alisado, exterior bruñido; decoración externa de boquique.

Fig. 12:3. Cto 325. Fragmento de cuerpo, pasta negra, textura porosa, desgrasante fino, arenoso y calizo, modelado a mano, cocción reducida; acabado interior alisado, exterior bruñido; decoración externa dos líneas de boquique.

Fig. 10:2. Cto 332. Fragmento de borde, pasta naranja, textura porosa, desgrasante fino, arenoso y calizo, modelado a mano, cocción reducida; acabado interior alisado, exterior bruñido.

Fig. 10:12. Cto 338. Fragmento de base, pasta negra, textura porosa,desgrasante medio, calizo, modelado a mano, cocción irregular; acabado interior alisado, exterior espatulado.

Fig. 7:5. Cto 340. Fragmento de borde, cuello y cuerpo, pasta gris, textura porosa, desgrasante medio, arenoso y calizo, modelado a mano, cocción reducida; acabado interior y exterior bruñido.

Fig. 12:1. Cto 343. Fragmento de borde y cuello, pasta negra, textura porosa, desgrasante grueso, caliza y cuarzo, modelado a mano, cocción reducida; acabado interior alisado, exterior bruñido; decoración externa de una línea de boquique.

Fig. 10:5. Cto 349. Fragmento de borde, pasta negra, textura porosa, desgrasante fino, arenoso, modelado a mano, cocción reducida; acabado interior alisado, exterior bruñido.

Fig. 12:9. Cto 350. Fragmento de cuerpo, pasta negra, textura porosa, desgrasante fino, calizo, modelado a mano, cocción reducida; acabado interior y exterior alisado; decoración exterior de líneas incisas rellenas de pasta blanca.

Fig. 8:1. Cto 352.Forma semicompleta, pasta negra, textura porosa, desgrasante fino, arenoso y calizo, modelado a mano, cocción irregular; acabado interior y exterior alisado.

Fig. 7:7. Cto 355. Fragmento de borde, cuello y cuerpo, pasta roja, textura porosa, desgrasante medio, arena y cuarzo, modelado a mano, cocción reducida; acabado interior y exterior bruñido. 
Fig. 10:14. Cto 357. Fragmento de base, pasta negra, textura porosa, desgrasante medio, caliza y cuarzo, modelado a mano, cocción reducida; acabado exterior espatulado; marcas externas impregnaciones en el interior.

Fig. 11:3. Cto 359. Fragmento de borde y cuello, pasta negra, textura porosa, desgrasante fino, arenoso y calizo, modelado a mano, cocción reducida; acabado interior y exterior alisado; decoración externa: una línea incisa bajo el borde y líneas de boquique formando guirnaldas; marcas externas de desgaste.

Fig. 10:4. Cto 360. Fragmento de borde, pasta roja, textura porosa, desgrasante grueso, Caliza y cuarzo, modelado a mano, cocción reducida; acabado interior y exterior bruñido.

Fig. 10:13. Cto 361. Fragmento de base, pasta negra y roja, textura porosa, desgrasante medio, arenoso y calizo, modelado a mano, cocción irregular; acabado interior y exterior espatulado; marcas externas de desgaste.

Fig. 7:1. Cto 362. Fragmento de borde, cuello y cuerpo, pasta negra, textura porosa, desgrasante fino, arenoso y calizo, modelado a mano, cocción reducida; acabado interior alisado, exterior bruñido.

Fig. 7:2. Cto 363. Fragmento de borde, cuello y cuerpo, pasta roja, textura porosa, desgrasante grueso, arena, caliza y cuarzo, modelado a mano, cocción reducida; acabado interior alisado, exterior bruñido.

Fig. 13:1. Cto 364. Fragmento de borde, pasta negra, textura porosa, desgrasante fino, arenoso y calizo, modelado a mano, cocción reducida; acabado interior y exterior bruñido.

Fig. 7:4. Cto 366. Fragmento de borde, cuello y cuerpo, pasta negra, textura porosa, desgrasante medio, arenoso, calizo y cuarcítico, modelado a mano, cocción reducida; acabado interior y exterior bruñido.

Fig. 9:2. Cto 367. Fragmento de borde y cuerpo, suspensión mamelón perforado, pasta negra y naranja, textura porosa, desgrasante medio, caliza y cuarzo, modelado a mano, cocción irregular; acabado interior espatulado, exterior alisado.

Fig. 8:2. Cto 369. Fragmento de borde y cuerpo, pasta negra y roja, textura porosa, desgrasante grueso, arena, caliza y cuarzo, modelado a mano, cocción irregular; acabado interior espatulado, exterior escobillado.

Fig. 7:8. Cto 371. Forma semicompleta, pasta roja, textura porosa, desgrasante fino, arenoso y calizo, modelado a mano, cocción reducida; acabado interior y exterior bruñido.

Fig. 9:3. Cto 375. Fragmento de borde y cuerpo, perforación de suspensión, pasta negra, textura porosa, desgrasante medio, mica, arena, caliza y cuarzo, modelado a mano, cocción reducida; acabado interior espatulado, exterior alisado; marcas externas de fuego.

Fig. 9:4. Cto 376. Fragmento de borde y cuello, pasta gris y roja, textura porosa, desgrasante medio, calizo, modelado a mano, cocción irregular; acabado interior y exterior alisado.

Fig. 12:6. Cto 378. Fragmento de cuerpo, pasta negra y roja, textura porosa, desgrasante fino, arenoso, modelado a mano, cocción irregular; acabado interior alisado, exterior bruñido; decoración externa, dos líneas de boquique.

Fig. 10:15. Cto 389. Fragmento de base, pasta gris, textura porosa, desgrasante medio, mica, arena, caliza y cuarzo, modelado a mano, cocción reducida; acabado interior y exterior alisado; marcas externas de desgaste.

Fig. 6:4. Cto 392. Fragmento de borde y cuerpo, pasta gris, textura porosa, desgrasante fino, arenoso y calizo, modelado a mano, cocción reducida; acabado interior y exterior bruñido.

Fig. 8:3. Cto 393. Fragmento de borde y cuerpo, pasta negra y amarillenta, textura porosa, desgrasante grueso, arena, caliza y cuarzo, modelado a mano, cocción irregular; acabado interior y exterior alisado.

Fig. 10:1. Cto 395. Fragmento de borde y cuello, pasta ocre oscuro, textura porosa, desgrasante fino, calizo, modelado a mano, cocción reducida; acabado interior y exterior bruñido.

Fig. 9:7. Cto 396. Fragmento de borde y cuello, pasta roja, textura porosa, desgrasante fino, arenoso y. calizo, modelado a mano, cocción irregular; acabado interior alisado, exterior bruñido.

Fig. 12:5. Cto 397. Fragmento de cuerpo, pasta negra y roja, textura porosa, desgrasante medio, arena, 
caliza y cuarzo, modelado a mano, cocción reducida; acabado interior alisado, exterior bruñido; decoración externa, dos líneas de boquique.

Fig. 10:6. Cto 398. Fragmento de borde, pasta negra y roja, textura porosa, desgrasante fino, arenoso, modelado a mano, cocción irregular; acabado interior y exterior bruñido.

Fig. 10:11. Cto 400. Fragmento de borde y cuello, pasta negra y naranja, textura porosa, desgrasante grueso, caliza y cuarzo, modelado a mano, cocción irregular; acabado interior y exterior bruñido.

Fig. 9:11. Cto 403. Fragmento de borde, pasta negra y naranja, textura porosa, desgrasante medio, arena y cuarzo, modelado a mano, cocción irregular; acabado interior y exterior bruñido.

Fig. 7:9. Cto 404. Fragmento de borde y cuerpo, pasta gris y roja, textura porosa, desgrasante grueso, caliza y cuarzo, modelado a mano, cocción irregular; acabado interior bruñido, exterior alisado.

Fig. 9:1. Cto 406. Fragmento de borde, pasta roja, textura porosa, desgrasante fino, arenoso y calizo, modelado a mano, cocción reducida; acabado interior alisado, exterior espatulado.

Fig. 9:12. Cto 407. Forma semicompleta, suspensión mamelón, pasta negra y roja, textura porosa, desgrasante fino, arenoso y calizo, modelado a mano, cocción irregular; acabado interior y exterior alisado; marcas externas de fuego.

Fig. 7:3. Cto 409. Fragmento de borde, cuello y cuerpo, suspensión perforación, pasta roja, textura porosa, desgrasante fino, mica, arena y caliza, modelado a mano, cocción reducida; acabado interior alisado, exterior bruñido.

Fig. 11:1. Cto 410. Forma semicompleta, pasta negra, textura porosa, desgrasante medio, arena, caliza y cuarzo, modelado a mano, cocción reducida; acabado interior bruñido, exterior alisado y bruñido; decoración en el interior del borde de boquique formando un zig-zag discontinuo relleno de pasta blanca, exterior una línea incisa bajo el borde rellena de pasta blanca, otra en la carena, en el cuerpo se desarrollan unas líneas incisas formando guirnaldas rellenas de pasta blanca.

Fig. 9:10. Cto 412. Fragmento de borde, pasta negra, textura porosa, desgrasante fino, arenoso y calizo, modelado a mano, cocción reducida; acabado interior y exterior bruñido.

Fig. 9:5. Cto 413. Fragmento de borde, pasta negra, textura porosa, desgrasante grueso, arena, caliza y cuarzo, modelado a mano, cocción irregular; acabado interior y exterior alisado.

Fig. 10:8. Cto 414. Fragmento de borde y cuello, pasta negra, textura porosa, desgrasante fino, arenoso y calizo, modelado a mano, cocción reducida; acabado interior y exterior bruñido.

Fig. 10:7. Cto 415. Fragmento de borde, pasta gris, textura porosa, desgrasante fino, arenoso, modelado a mano, cocción irregular; acabado interior y exterior bruñido.

Fig. 12:4. Cto 416. Fragmento de cuerpo, pasta negra y roja, textura porosa, desgrasante fino, arenoso y calizo, modelado a mano, cocción reducida; acabado interior espatulado, exterior bruñido; decoración externa de tres líneas paralelas de boquique.

Fig. 6:1. Cto 420. Forma semicompleta, pasta gris, textura porosa, desgrasante fino, arenoso y calizo, modelado a mano, cocción reducida; acabado interior y exterior bruñido.

Fig. 10:16. Cto 422. Fragmento de base, pasta negra, textura porosa, desgrasante medio, arena, caliza y cuarzo, modelado a mano, cocción reducida; acabado interior y exterior alisado.

Fig. 10:9. Cto 423. Fragmento de borde, cuello y cuerpo, pasta negra y roja, textura porosa, desgrasante grueso, arena, caliza y cuarzo, modelado a mano, cocción irregular; acabado interior alisado, exterior bruñido.

Fig. 13:3. Cto 424. Fragmento de borde y cuello, pasta gris y naranja, textura porosa, desgrasante fino, arenoso y calizo, modelado a mano, cocción irregular; acabado interior y exterior bruñido.

Fig. 6:3. Cto 425. Fragmento de borde, cuello y cuerpo, pasta roja, textura porosa, desgrasante fino, arenoso y calizo, modelado a mano, cocción irregular; acabado interior y exterior bruñido. 
Fig. 10:3. Cto 426. Fragmento de borde, pasta negra y roja, textura porosa, desgrasante fino, arenoso y calizo, modelado a mano, cocción reducida; acabado interior y exterior alisado.

Fig. 9:6. Cto 429. Fragmento de borde y cuerpo, suspensión mamelón, pasta negra, textura porosa, desgrasante grueso, arena, caliza y cuarzo, modelado a mano, cocción reducida; acabado interior y exterior alisado.

Fig. 9:8. Cto 431. Fragmento de borde y cuerpo, pasta negra y roja, textura porosa, desgrasante grueso, arena, caliza y cuarzo, modelado a mano, cocción irregular; acabado interior espatulado, exterior alisado.

Fig. 10:10. Cto 434. Fragmento de borde, pasta negra, textura porosa, desgrasante medio, caliza y cuarzo, modelado a mano, cocción reducida; acabado interior y exterior bruñido.

Fig. 12:8. Cto 435. Fragmento de borde, pasta negra, textura porosa, desgrasante fino, arenoso y calizo, modelado a mano, cocción reducida; acabado interior alisado, exterior bruñido; decoración exterior bajo el borde de un punto inciso relleno de pasta blanca.

Fig. 7:6. Cto 437. Fragmento de borde, cuello y cuerpo, pasta negra y naranja, textura porosa, desgrasante fino, calizo, modelado a mano, cocción reducida; acabado interior alisado, exterior bruñido.

Fig. 13:4. Cto 438. Fragmento de borde y cuerpo, pasta negra, textura porosa, desgrasante medio, arena, caliza y cuarzo, modelado a mano, cocción reducida; acabado interior y exterior bruñido; decoración en el exterior del borde y cuerpo de digitaciones; marcas externas de fuego.

Fig. 12:7. Cto 447. Fragmento de cuerpo, pasta negra, textura porosa, desgrasante fino, arenoso y calizo, modelado a mano, cocción reducida; acabado interior y exterior bruñido; decoración exterior de líneas incisas y puntillado.

Fig. 6:7. Cto 506. Útil de cuarcita sobre lasca con retoque marginal.

Fig. 6:6. Cto 507. Útil de sílex sobre lasca con retoque en el extremo distal.

Fig. 6:8. Cto 510. Útil de cuarcita sobre lasca con talla marginal. Perforador.

Fig. 6:5. Cto 511. Canto rodado de cuarcita con muescas bifaciales en ambos laterales.

Fig. 6:9. Cto 513. Punzón de hueso.

\section{Materiales de la UE. 109:}

Fig. 13:2. Cto 440. Forma semicompleta, pasta roja, textura porosa, desgrasante grueso, mica, arena, caliza y cuarzo, modelado a mano, cocción irregular; acabado interior y exterior alisado; marcas externas de fuego.

\section{Materiales de la UE. 111:}

Fig. 14:1. Cto 280. Fragmento de borde, pasta naranja, textura porosa, desgrasante fino, mica y caliza, modelado a mano, cocción irregular; acabado indefinible; desgaste superficial generalizado.

Fig. 14:4. Cto 281. Mamelón, pasta naranja, textura porosa, desgrasante fino, mica y caliza, modelado a mano, cocción irregular; desgaste superficial generalizado.

Fig. 14:3. Cto 282. Fragmento de borde, pasta negra y roja, textura porosa, desgrasante grueso, mica, arena, caliza y cuarzo, modelado a mano, cocción irregular; tratamiento exterior alisado; desgaste superficial generalizado.

Fig. 14:2. Cto 283. Fragmento de borde, pasta negra y naranja, textura porosa, desgrasante fino, mica, caliza y cuarzo, modelado a mano, cocción irregular; acabado interior y exterior alisado.

\section{Materiales de la UE. 113:}

Fig. 14:6. Cto 284. Forma semicompleta, suspensión mamelón perforado, pasta naranja, textura porosa, 
desgrasante medio, mica, caliza y cuarzo, modelado a mano, cocción irregular; acabado interior y exterior bruñido; desgaste superficial generalizado.

Fig. 14:5. Cto 286. Fragmento de borde, pasta negra, textura porosa, desgrasante medio, mica, caliza y cuarzo, modelado a mano, cocción reducida; acabado interior alisado, exterior bruñido.

\section{BIBLIOGRAFÍA}

ALMAGRO GORBEA, M. (1977: El Bronce Final y el periodo Orientalizante en Extremadura. Bibliotheca Praehistorica Hispanica XIV, Madrid.

AMORES y RODRÍGUEZ HIDALGO, J.M. (1984-85): "Cogotas en Carmona y panorama general del fenómeno en Andalucía Occidental”. MAINAKE, VI-VII. MÁLAGA. Págs. 73-86.

ARTEAGA, O. (1982): “Los Saladares-80. Nuevas directrices para el estudio del horizonte protoibérico en el Levante Meridional y Sudeste de la Península". Huelva Arqueológica $V$.

ARTEAGA, O. y SCHUBART, H (1980): "Fuente Alamo. Excavaciones de 1977”. Noticiario Arqueológico Hispánico, 9. Págs. 245-291.

AUBET, M.E. (1975): La necrópolis de Setefilla, en Lora del Río (Sevilla). C.S.I.C. Barcelona.

AUBET, M.E. y otros. (1983): La Mesa de Setefilla. Lora del Río (Sevilla). Campaña de 1979. Excavaciones Arqueológicas en España, 122.

BANDERA, M.L. de la y otros. (1993): "Montemolín. Evolución del asentamiento durante el Bronce Final y el período Orientalizante". Anales de Arqueología Cordobesa, 4. Págs. 15-48.

BELÉN, M. y ESCACENA, J.L. (1992): "Las Comunidades Prerromanas de Andalucía occidental". Paleoetnología de la Península Ibérica. Complutum 2-3: 65-87.

CARDENETE, R. y otros. (1989): "Excavaciones Arqueológicas de Urgencia en el solar de la calle Costanilla Torre del Oro s/n. Carmona (Sevilla)". Anuario Arqueológico de Andalucíal1989. Actividades de Urgencia. Págs. 563-574.

— (1990): "Excavaciones arqueológicas de urgencia en el solar de la calle Plaza de Santiago no 1". Anuario Arqueológico de Andalucíal1990. III Actividades de Urgencia.

CARRIAZO, J. de M. y RADDATZ, K. (1960): "Primicias de un corte estratigráfico en Carmona". Archivo Hispalense, 103-104. Págs. 333-369.

DELIBES, G.; FERNÁNDEZ-MIRANDA, M. (1986-87): “Aproximación a la cronología del grupo Cogotas I". Zephyrus XXXIX-XL. Págs. 17-30.

ESCACENA, J.L. y FRUTOS, G. (1985): "Estratigrafía de la Edad del Bronce en el monte del Berrueco (Medina Sidonia, Cádiz)”. Noticiario Arqueológico Hispánico, 24. Págs. 7-40.

ESCACENA, J.L. y BELÉN, M. (1991): “Sobre la cronología del horizonte fundacional de los asentamientos tartésicos". Cuadernos del Suroeste, 2. Págs. 9-42.

FERNÁNDEZ-POSSE, M.D. (1982): “Consideraciones sobre la técnica de Boquique”. Trabajos de Prehistoria 39. Págs. 137-159.

HARRIS, E.C. (1979): Principles of Archaeological Stratigraphy. Academic Press. Londres y San Diego.

- (1991): Principios de estratigrafía arqueológica. Barcelona.

JIMENO, A. y FERNÁNDEZ MORENO. (1991): Los Tolmos de Caracena (Soria). Campañas de 1981 y 1982. Aportación al Bronce Medio de la Meseta. Excavaciones Arqueológicas en España, 161.

MALUQUER DE MOTES, J. (1956): "La técnica de incrustación de boquique y la dualidad de tradiciones cerámicas en la meseta durante la Edad del Hierro". Zephyrus VII. Págs. 179-206. 
MOLINA GONZÁLEZ, F. (1978): "Definición y sistematización del Bronce Tardío y Final en el Sudeste de la Península Ibérica". Cuadernos de Prehistoria de la Universidad de Granada, 3. Págs. 159-233.

MOLINA GONZÁLEZ, F. y PAREJA, E. (1975): Excavaciones en la Cuesta del Negro (Purullena, Granada). Campaña de 1971. Excavaciones Arqueológicas en España, 86.

MOLINA GONZÁLEZ, F. y ARTEAGA, O. (1975): "Problemática y diferenciación en grupos de la cerámica con decoración excisa en la Península Ibérica". Cuadernos de Prehistoria de la Universidad de Granada l. Págs. 175-214.

PELLICER, M. y AMORES, F. (1985): "Protohistoria de Carmona. Los cortes estratigráficos CA 80/A y CA 80/B”. Noticiario Arqueológico Hispánico 22. Págs. 55-189.

PÉREZ MACÍAS, J.A. (1983): "Introducción al Bronce Final en el Noroeste de la provincia de Huelva". Habis, 14. Págs. 207-237.

RIVERO, M.C. (1972-73): "Materiales inéditos de la Cueva de Boquique. Datos para una nueva sistematización de la Edad del Bronce en Extremadura". Zephyrus, XXIII-XXIV. Págs. 101-130.

SCHUBART, H. y ARTEAGA, O. (1986): "Fundamentos arqueológicos para el estudio socio-económico y cultural del área del Argar". Homenaje a Luis Siret. Sevilla. Págs. 289-307. 


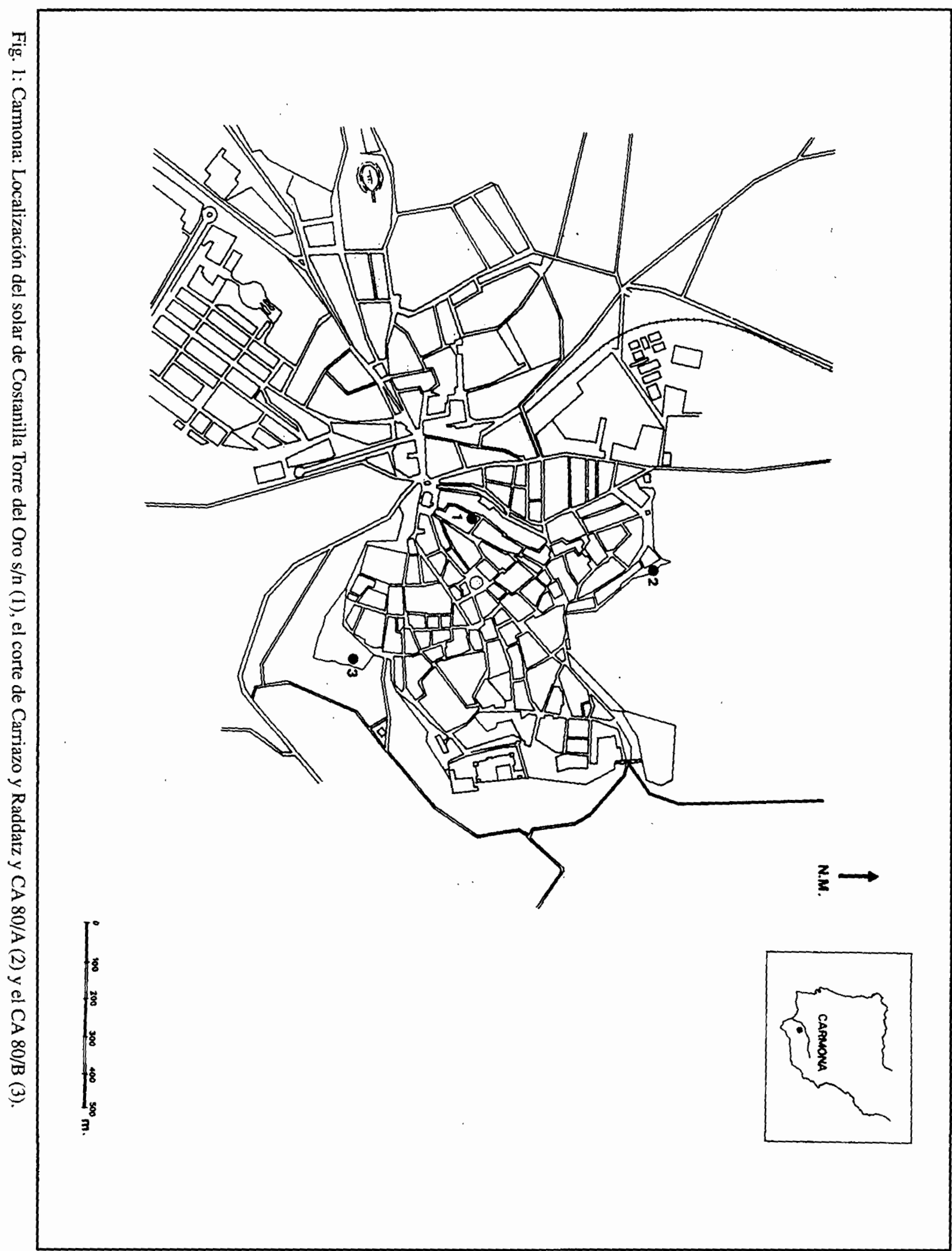




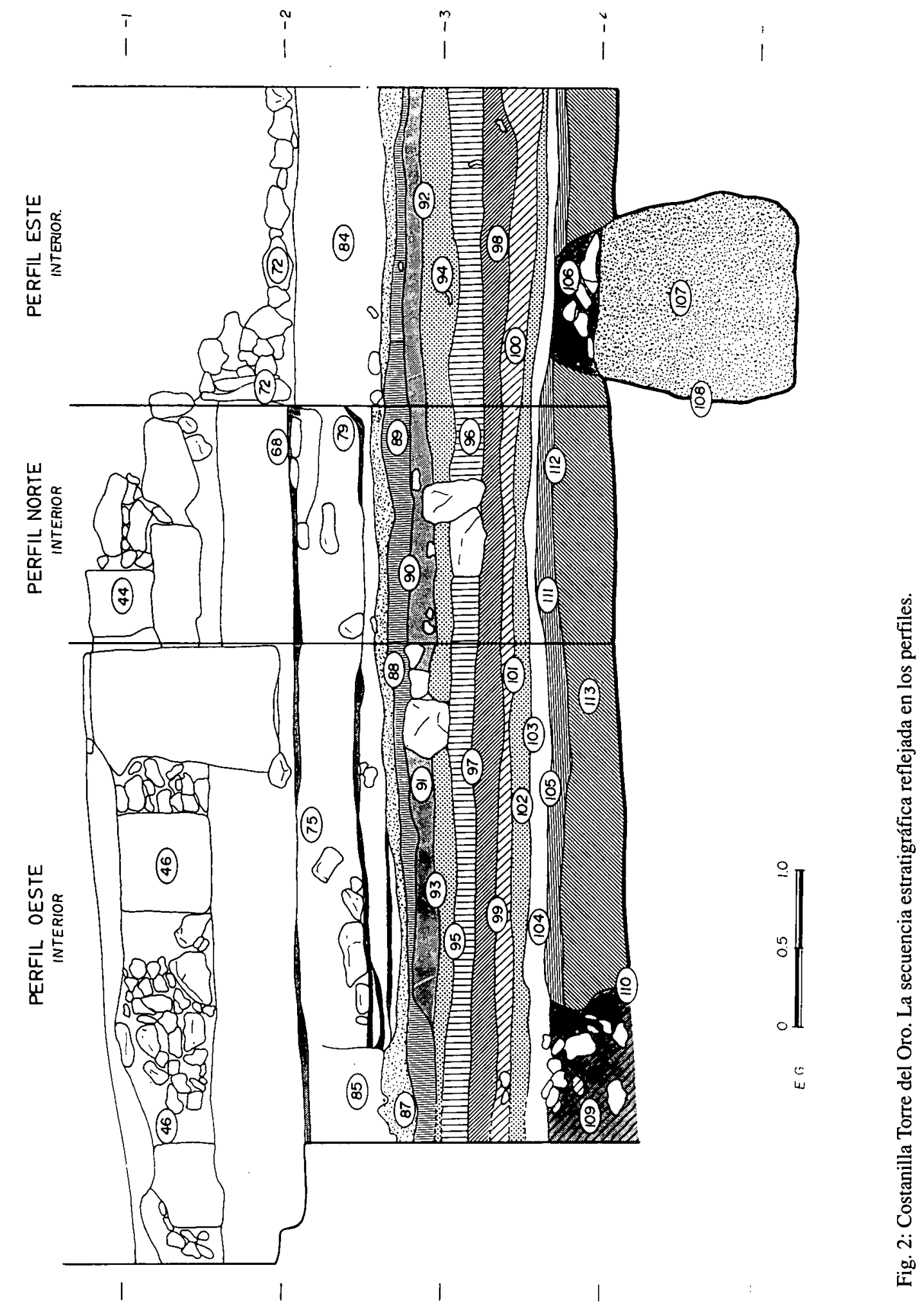



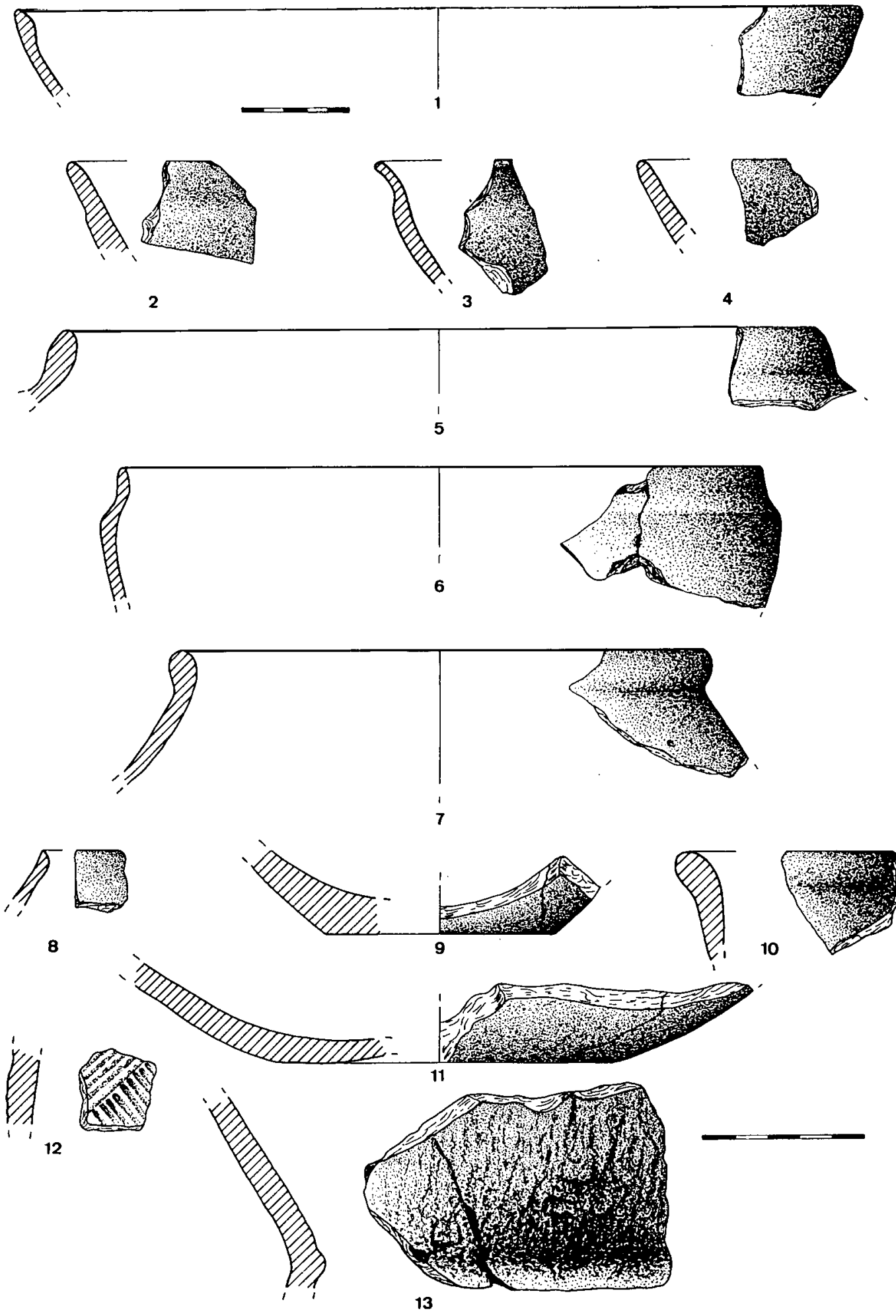

Fig. 3: Costanilla Torre del Oro. Materiales de la UE. 100. 

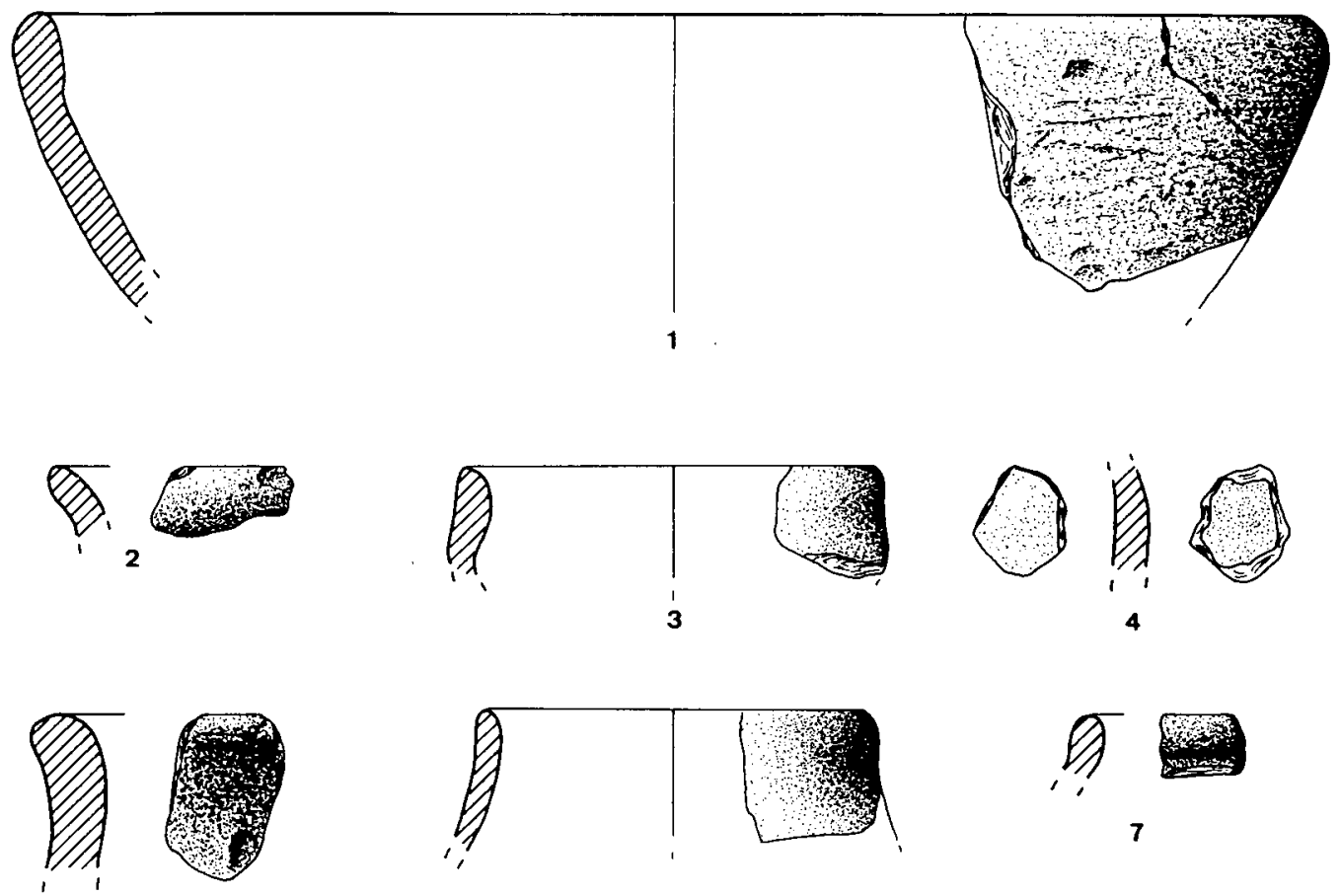

5

6

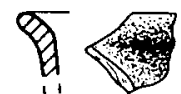

8
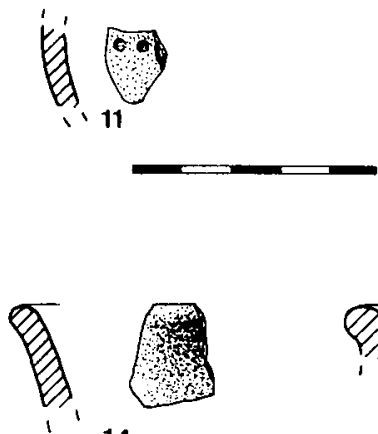

14

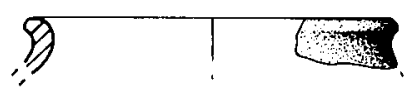

9
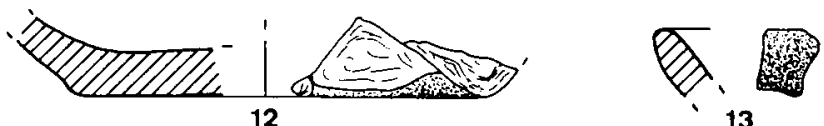

13

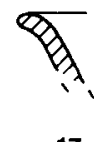

17

Fig. 4: Costanilla Torre del Oro. Materiales de las UUEE. 102 (1-13) y 104 (14-17). 

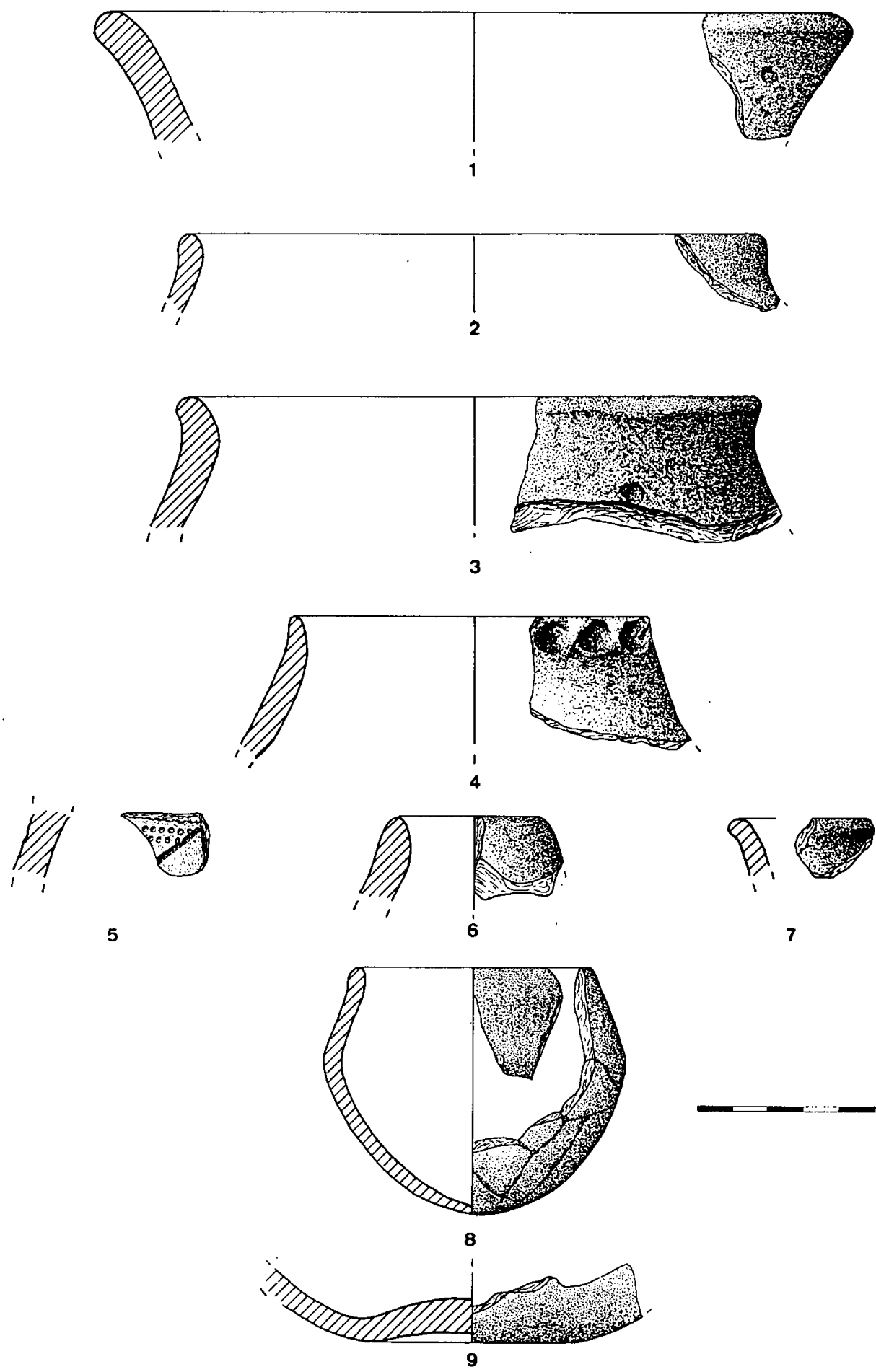

Fig. 5: Costanilla Torre del Oro. Materiales de la UE. 106. 

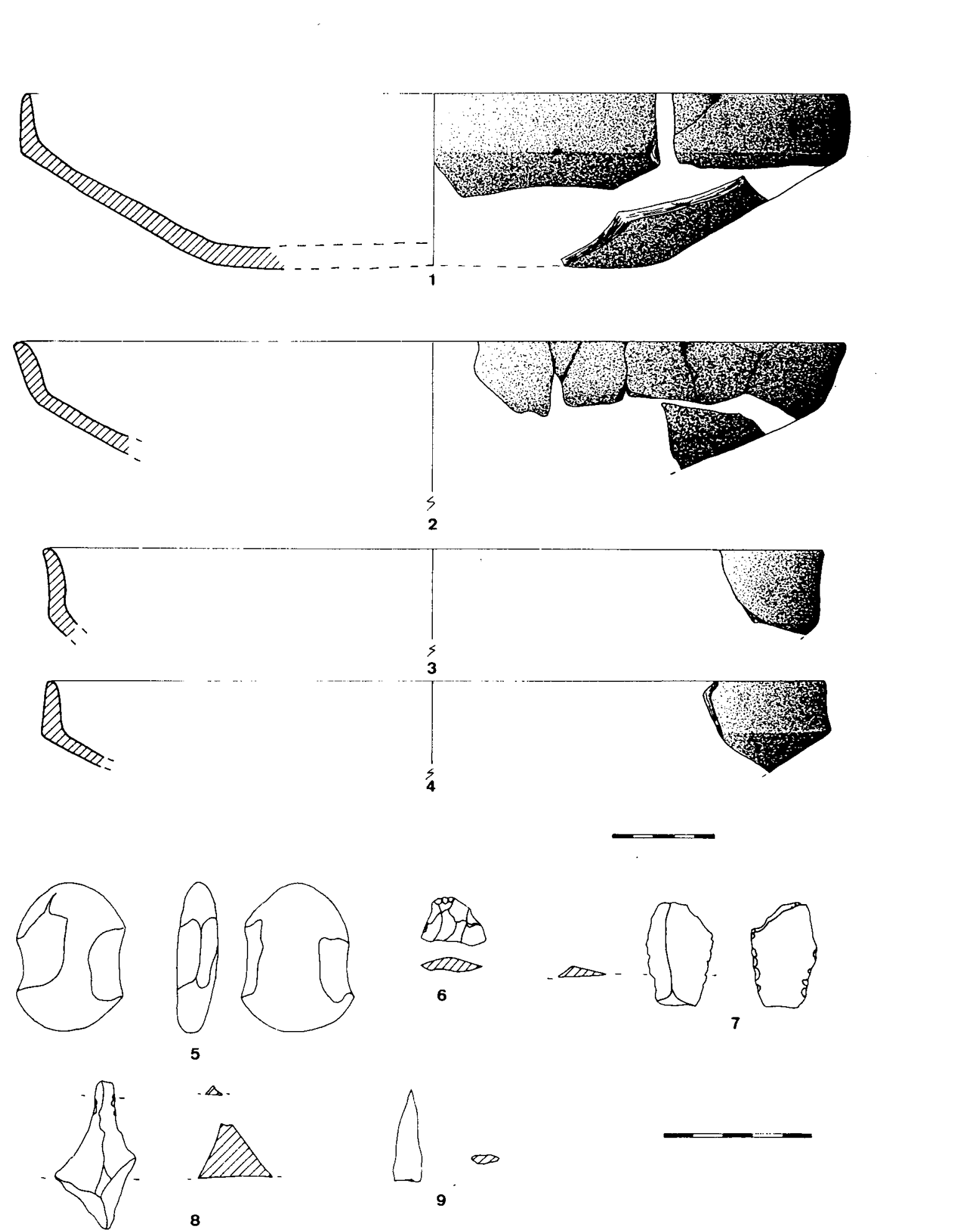

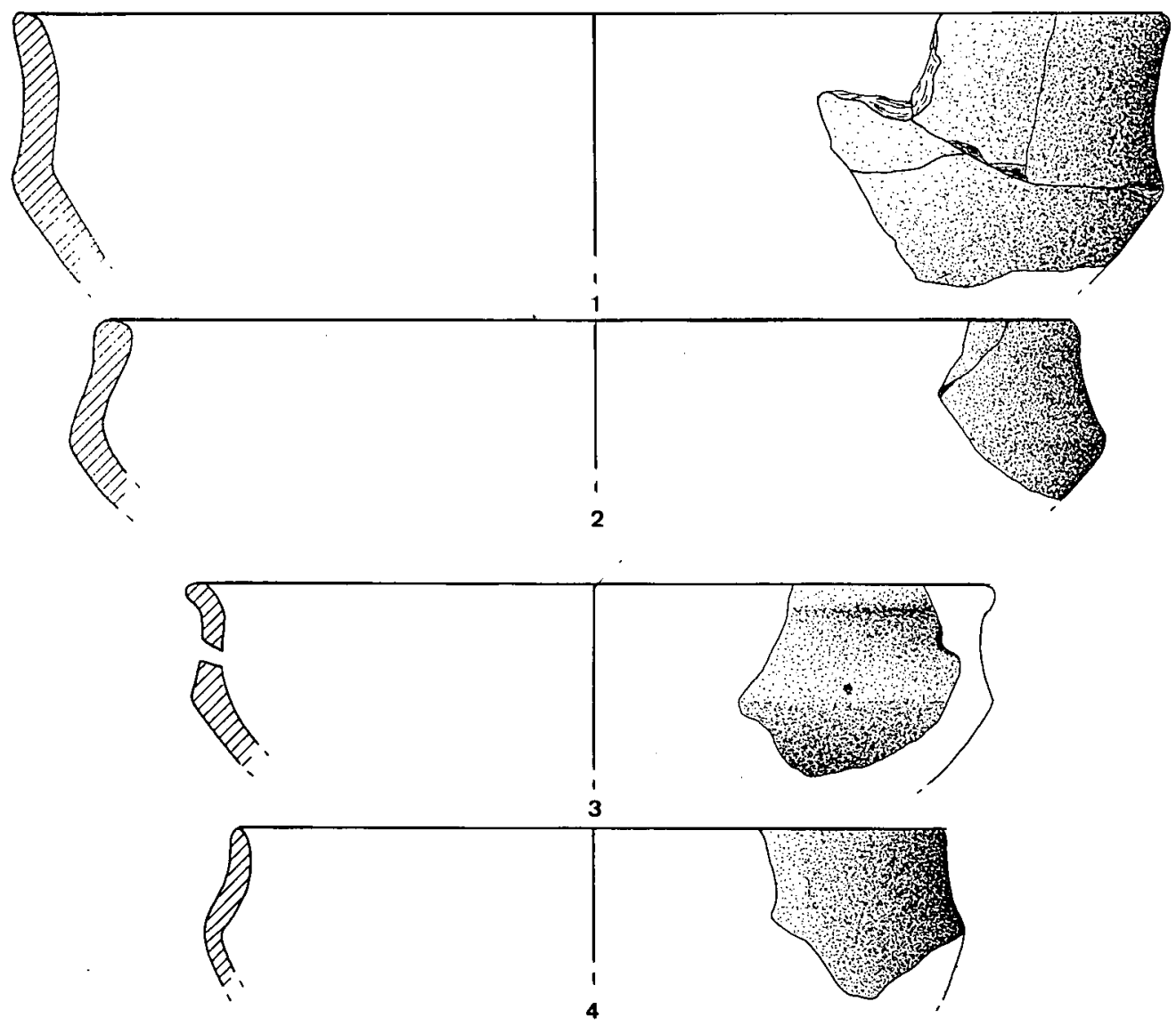

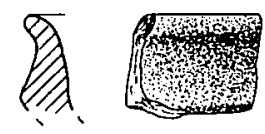

5

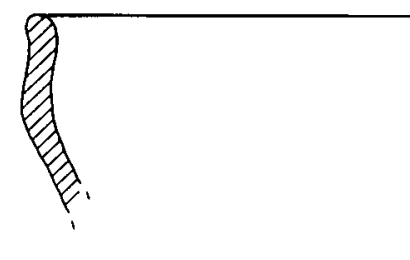

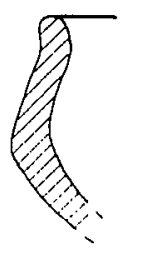

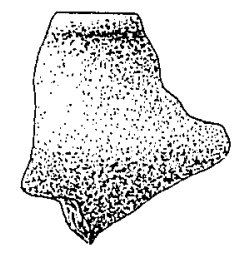

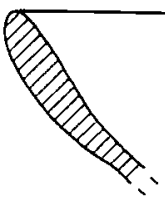

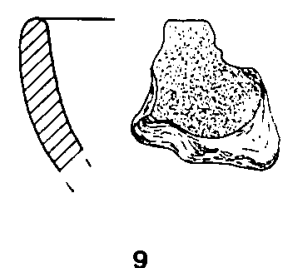

Fig. 7: Costanilla Torre del Oro. Materiales de la UE. 107. 

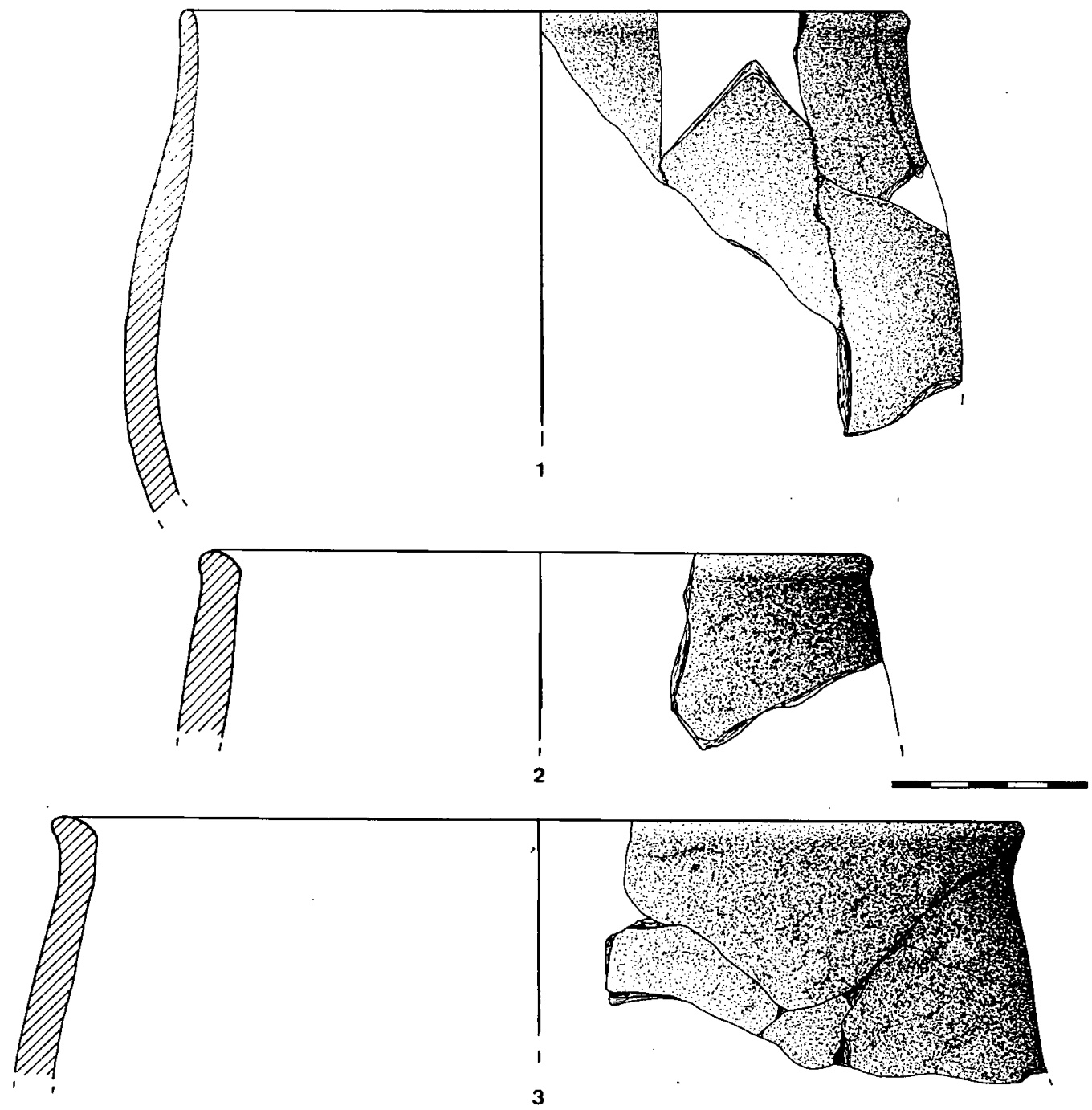

Fig. 8: Costanilla Torre del Oro. Materiales de la UE. 107. 

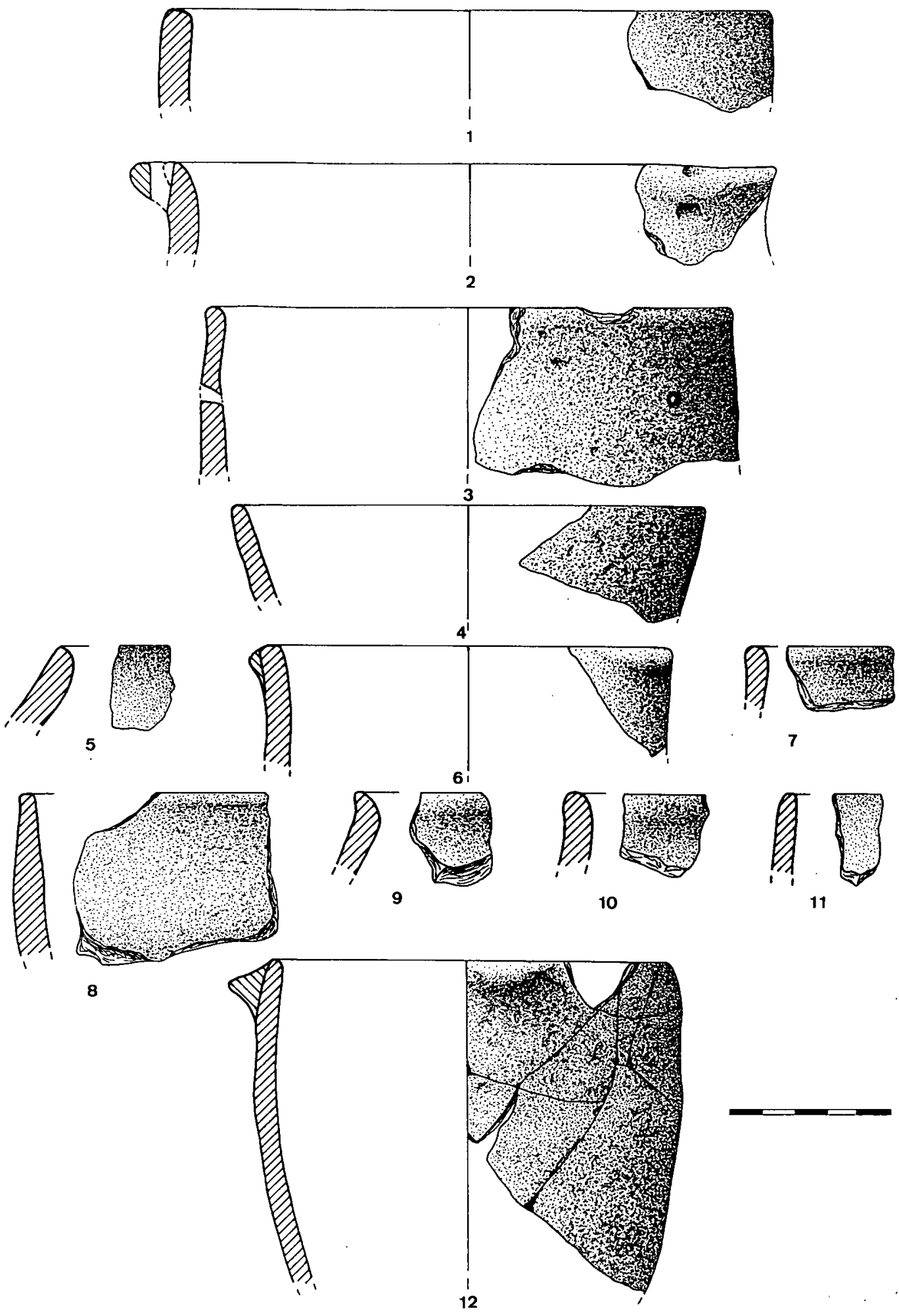

Fig. 9: Costanilla Torre del Oro. Materiales de la UE. 107. 


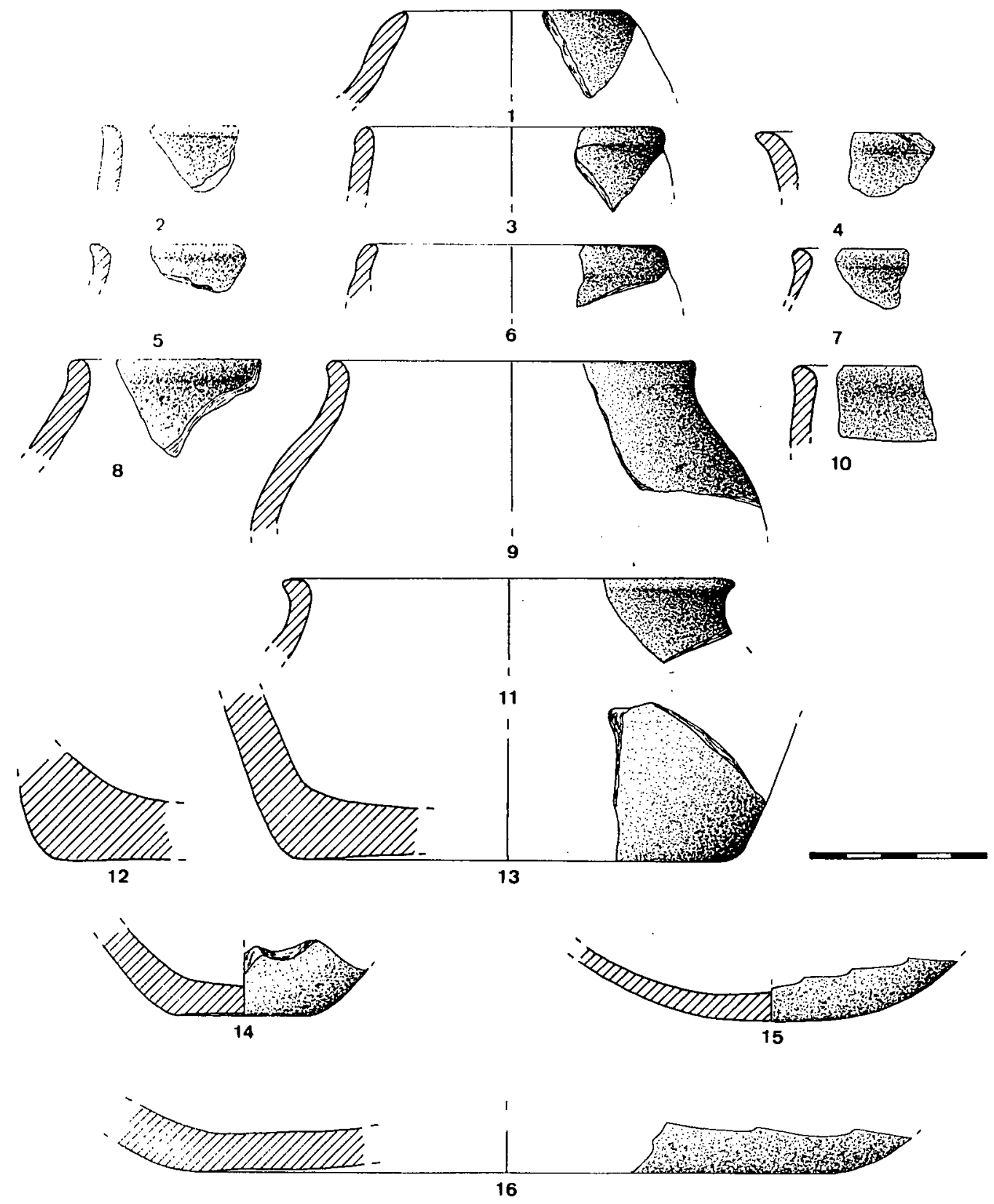

Fig. 10: Costanilla Torre del Oro. Materiales de la UE. 107. 

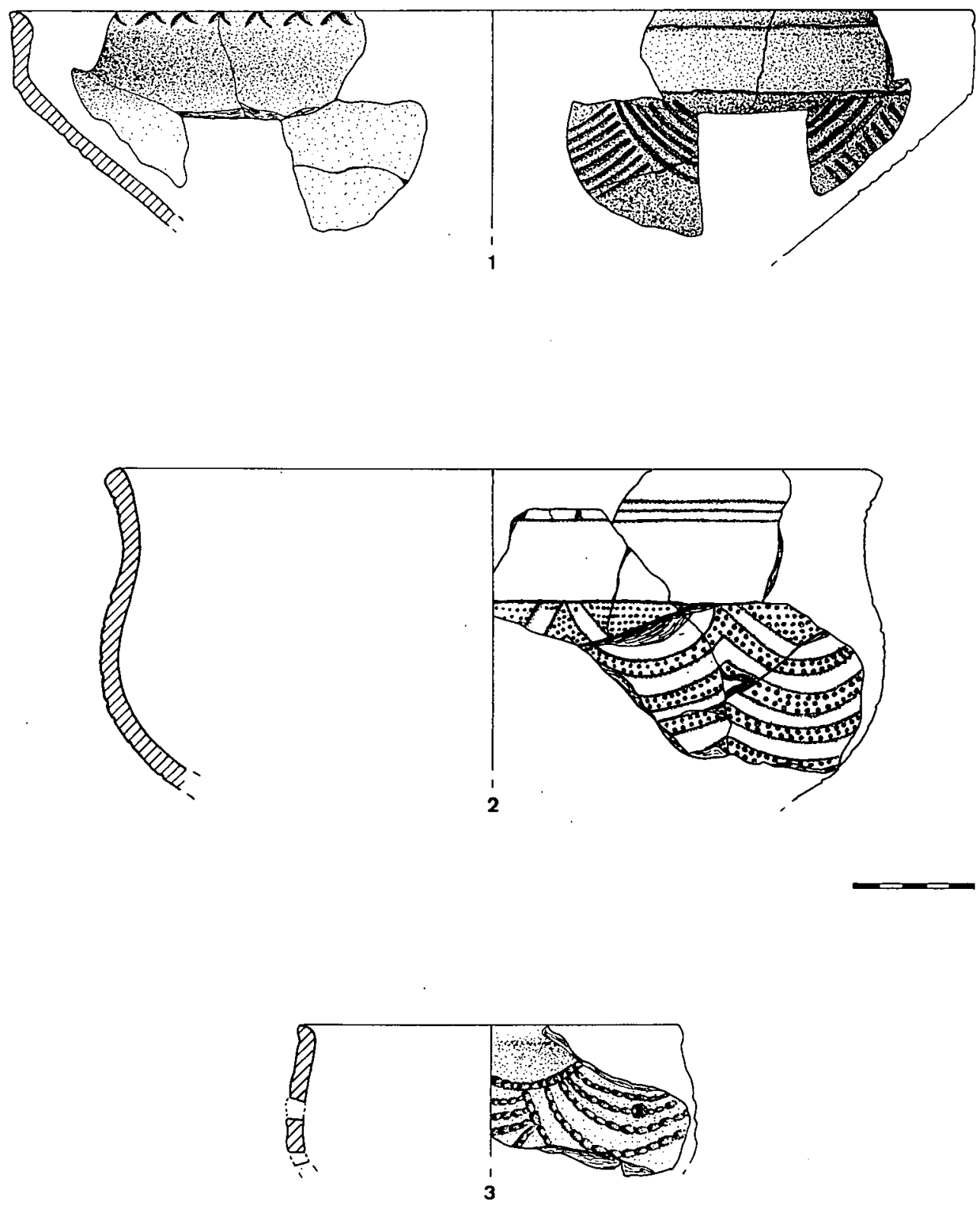

Fig. 11: Costanilla Torre del Oro. Materiales de la UE. 107. 

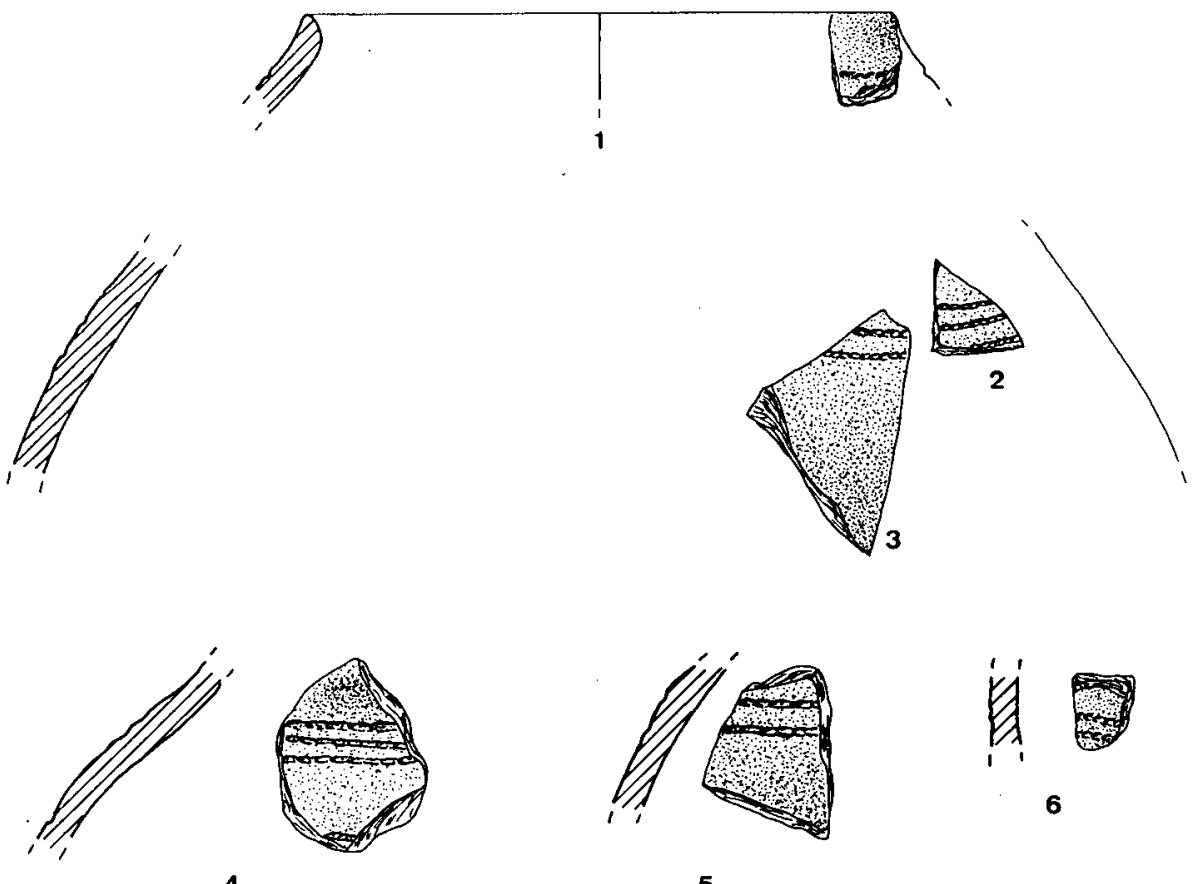

4

5
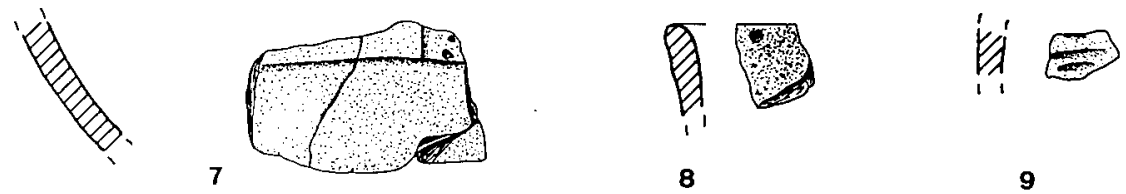

Fig. 12: Costanilla Torre del Oro. Materiales de la UE. 107. 

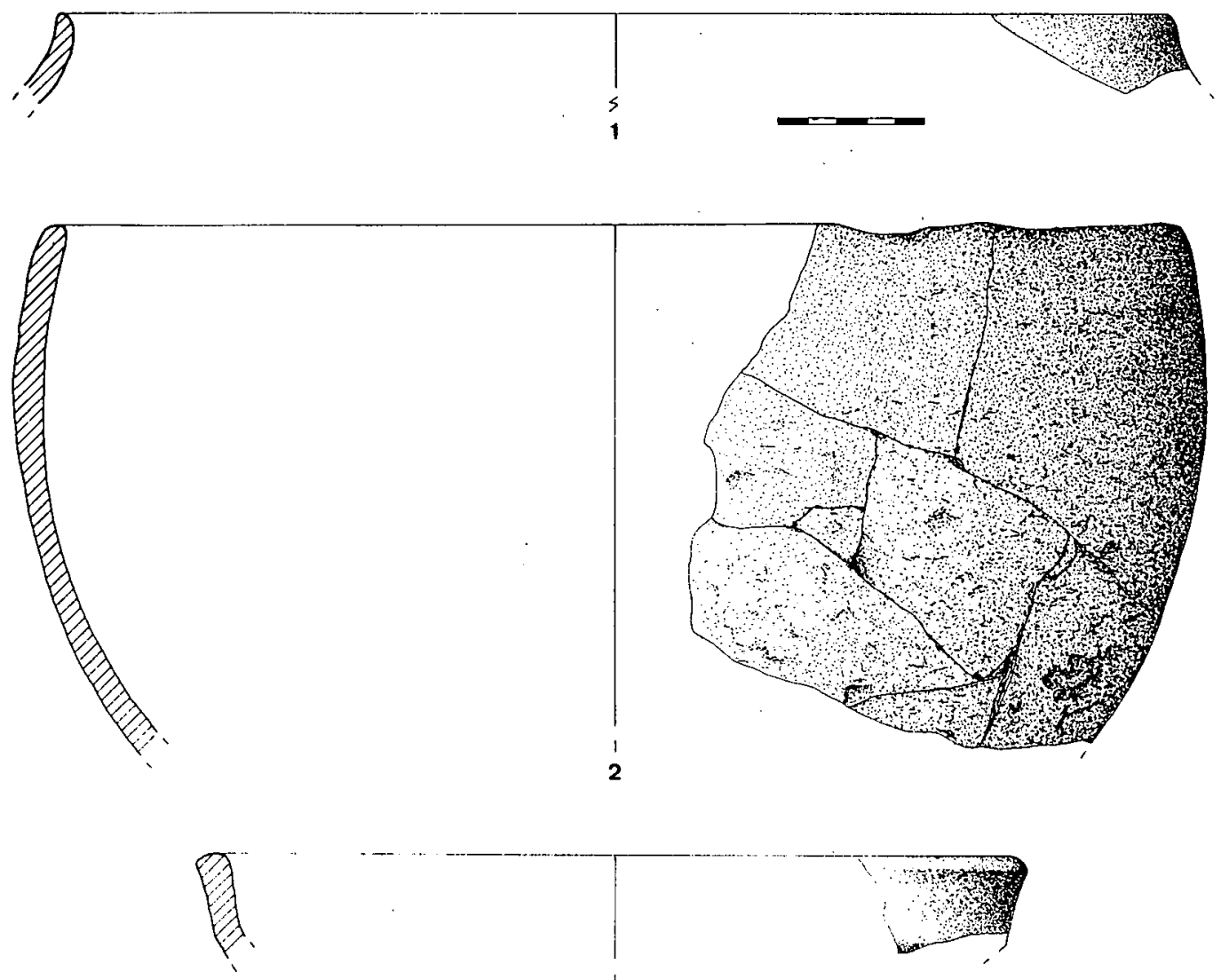

3
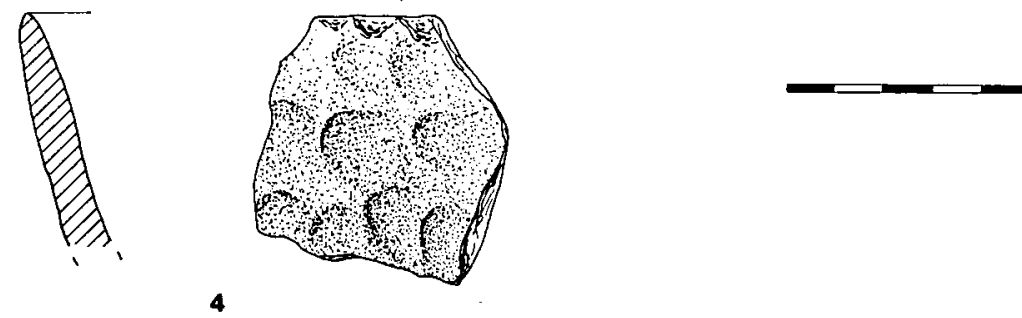

Fig. 13: Costanilla Torre del Oro. Materiales de las UUEE. 107 (1, 3 y 4) y 109 (2). 


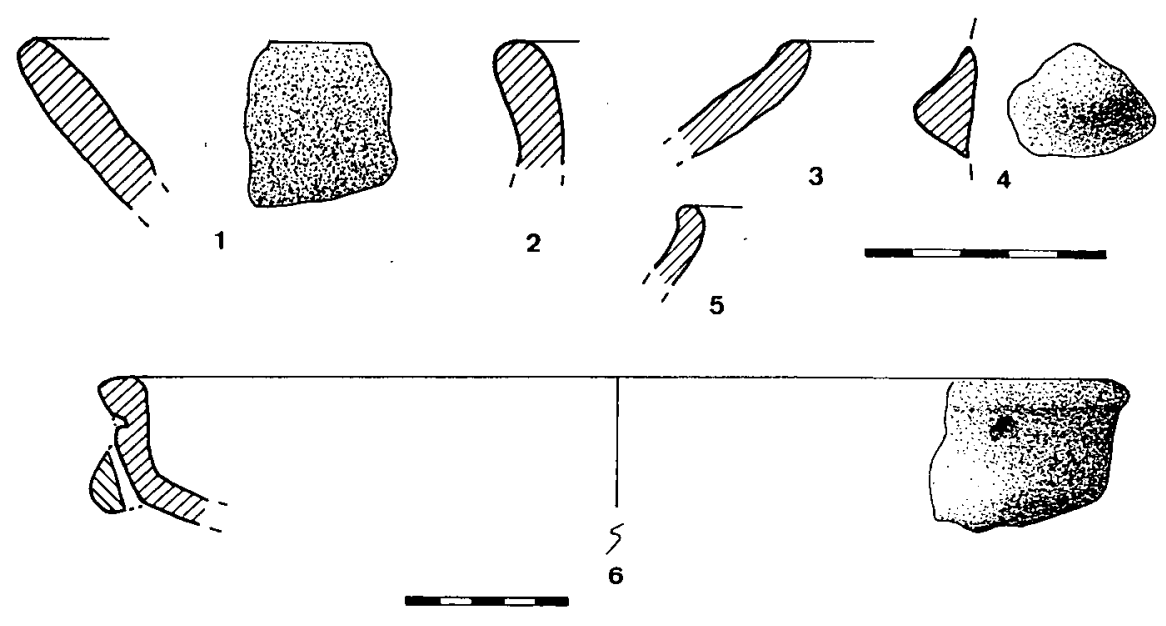

Fig. 14: Costanilla Torre del Oro. Materiales de las UUEE. 111 (1-4) y 113 (5 y 6). 